\title{
Laminar, Transitional, and Turbulent Heating on Mid Lift-to-Drag Ratio Entry Vehicles
}

\author{
Brian R. Hollis* \\ NASA Langley Research Center, Hampton, VA, 23681 \\ Kevin E. Hollingsworth ${ }^{\dagger}$ \\ Aerospace Computing, Inc., Hampton, VA 23681
}

\begin{abstract}
The boundary-layer transition characteristics and convective aeroheating levels on mid lift-to-drag ratio entry vehicle configurations have been studied through wind tunnel testing. Several configurations were investigated, including elliptically-blunted cylinders with both circular and elliptically-flattened cross sections, biconic geometries based on launch vehicle dual-use shrouds, and parametrically-optimized analytic geometries. Vehicles of this class have been proposed for high-mass Mars missions, such as sample return and crewed exploration, for which the conventional sphere-cone entry-vehicle geometries of previous Mars missions are insufficient. Testing was conducted at Mach 6 over a range of Reynolds numbers sufficient to generate laminar, transitional, and turbulent flow. Transition onset locations - both straight-line and cross-flow - and heating rates were obtained through global phosphor thermography. Supporting computations were performed to obtain heating rates for comparison with the data. Laminar data and predictions agreed to well within the experimental uncertainty. Fully-turbulent data and predictions also agreed well. However, in transitional flow regions, greater differences were observed. Additional aerodynamic performance data were also generated through Modified-Newtonian analyses of the geometries.
\end{abstract}

\section{Nomenclature}

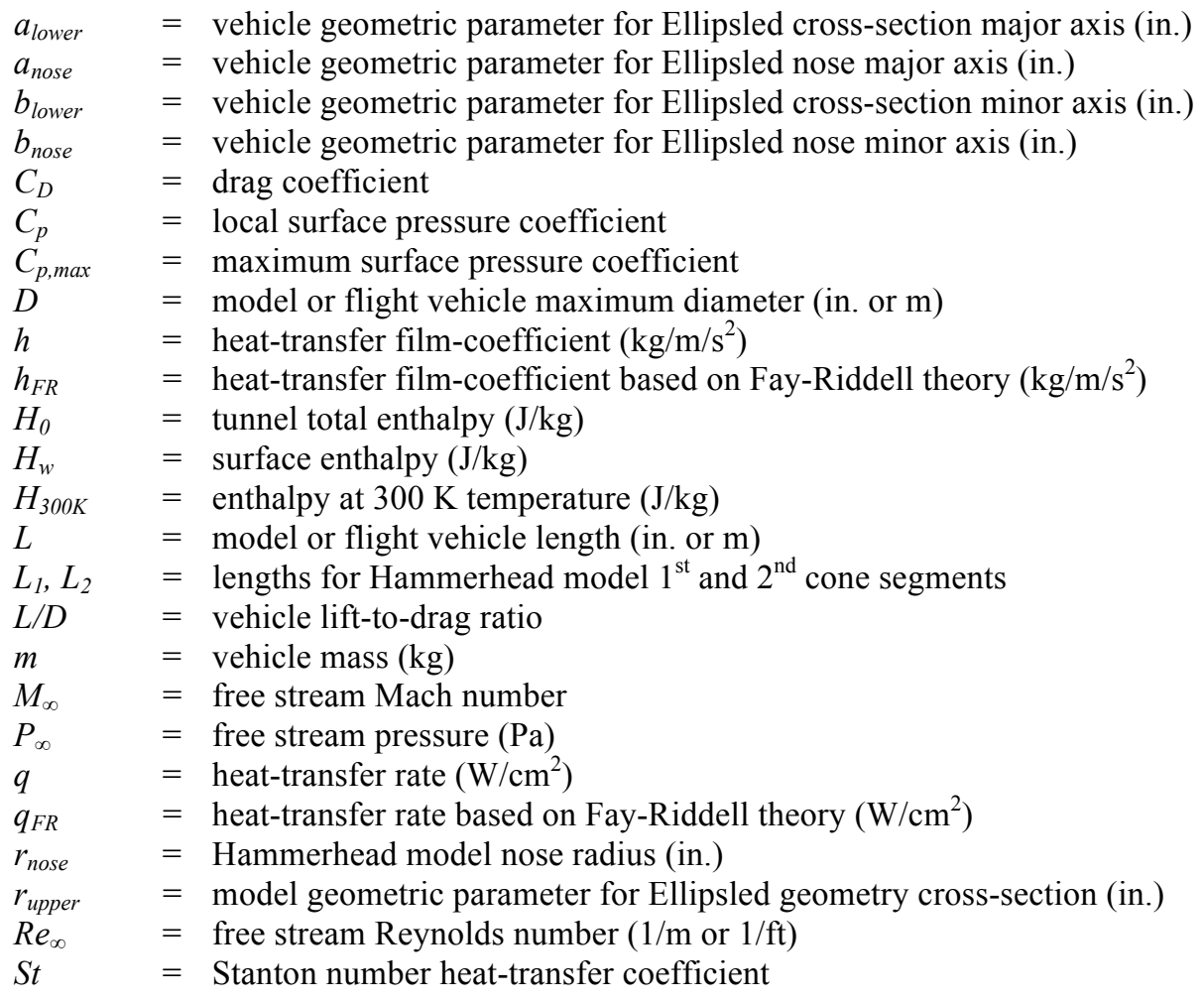

\footnotetext{
* Aerospace Engineer, Aerothermodynamics Branch, AIAA Associate Fellow

${ }^{\dagger}$ Principal Engineer, Supersonic/Hypersonic Test Branch
} 


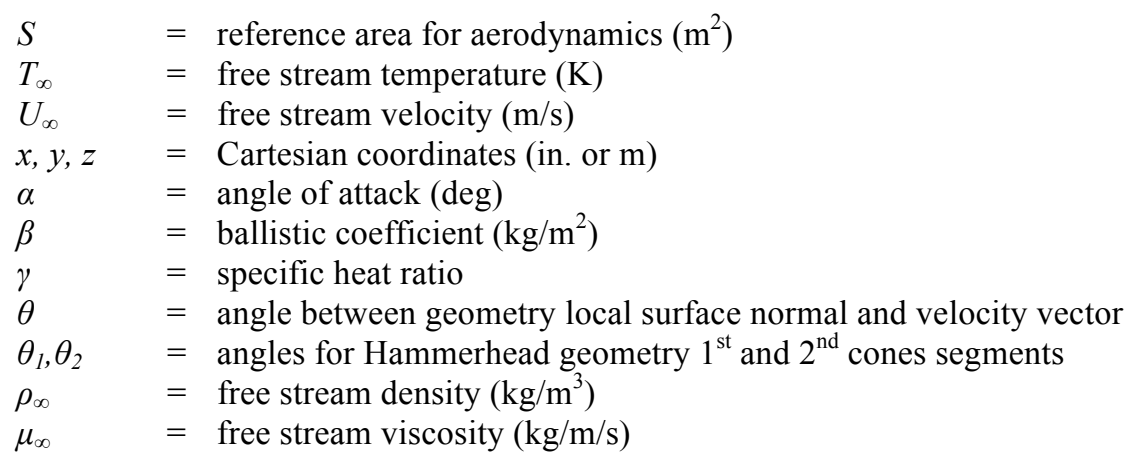

\section{Background}

The long-term goals of NASA's Mars exploration program include both robotic sample return missions and long-duration crewed missions. Such missions will require safe and precise landing of much larger masses than any previous Mars missions (10 mt to $50 \mathrm{mt}$ ). Recent systems analysis studies (Refs. 1 - 4) have demonstrated that the heritage, 70-deg sphere-cone entry vehicle architecture employed by every NASA mission to Mars from Viking to Mars Science Laboratory (MSL) does not provide sufficient aerodynamic performance to decelerate and precisely target the desired landing site in the thin atmosphere of Mars. One of the architectures identified by these studies that would enable such missions is a Mid- $L / D(\sim 0.4$ to 0.8$)$ entry-vehicle geometry. Mid- $L / D$ geometries have also been identified as candidates for outer planets missions (e.g. Neptune) for which aerocapture will be employed (Ref. $5)$.

In order to ensure the success of a mission in which a Mid- $L / D$ geometry is employed, the aerodynamic and aerothermodynamic (both convective heating and shock-layer radiation) environments must be understood. Because Mid- $L / D$ geometries do not have the test, evaluation, and flight heritage of sphere-cone geometry entry vehicles, the current study was conducted in order to obtain experimental information on the convective aeroheating environment with a focus on boundary-layer transition behavior and turbulent heating levels. An engineering-level analysis was also conducted to provide aerodynamic performance comparisons between the geometries.

\section{Mid- $L / D$ Geometries}

Various geometries have been proposed and studied to meet the Mid- $L / D$ entry vehicle requirements depending on the mission in question. In the present study, three separate classes of geometries were studied in order to generate a parametric database on convective heating and boundary-layer transition that will be applicable to future design studies. The common thread between all geometries was the specification of a $30 \mathrm{~m}$ flight vehicle length with a length to max-diameter ratio of 3:1, which was the baseline defined in Refs. 1 - 4. For wind tunnel testing, a scale factor of 0.01016 was applied to produce $0.3048 \mathrm{~m}$ (12-in.) long models. Also, the wind tunnel models were fabricated with a narrow flat on the top (leeside) surface to aid in model positioning and alignment; in no way did this change from the nominal geometries affect the data on the bottom (wind-side) of the models.

\section{A. Ellipsled Geometries}

"Ellipsled" geometries, which consist of an elliptically-blunted nose and a cylindrical aftbody, have been proposed for various exploration missions that require aerocapture (e.g. Refs. 5, 6). Two sub-classes of ellipsleds were considered herein: axisymmetric and flattened. The axisymmetric ellipsled has a circular cross-section and the flattened ellipsled cross-section is split between a circular top-half and an elliptical bottom-half. Five ellipsled geometries were tested: for the axisymmetric geometries, the ellipticity of the nose was varied in the longitudinal direction to create different nose bluntness factors; while for the flattened ellipsleds the cross-sectional ellipticity of the lower half of the geometry was varied to produce a flatter bottom. These geometries are shown in Figure 1 and Figure 2. The geometric parameters are defined in Figure 3 and listed in Table 1. The naming convention employed is "Ellipsled-xxx-yyy", where "xxx" represents the nose axes ratio $\left(a_{\text {nose }} / b_{\text {nose }}\right)$ and "yyy" represents the lower-body cross-section axes ratio $\left(a_{\text {lower }} / b_{\text {lower }}\right)$. Note that Ellipsled-2.00-1.00 is shown twice as it represents the nominal case: $a_{\text {lower }} / b_{\text {lower }}=1$, of the flattened ellipsled family.

\section{B. COBRA Optimized Geometries}

The "COBRA" (Co-Optimization of Blunt-body Re-entry Analysis) geometries were taken from Ref. 7 in which an optimization algorithm was developed to meet certain mission performance criteria, e.g. landed mass, convective 
heating rate, aerodynamic performance, etc. Starting from a spherically-capped cylinder (equivalent to the Ellipsled-1.00-1.00 geometry), a family of optimized geometries were generated that met the criteria for a high-mass Mars entry mission. Three representative geometries: COBRA-8459B, COBRA-14297B and COBRA-14888B, were selected from this family for testing. These geometries are shown in Figure 4. Additional information on these geometries is provided in Ref. 7.

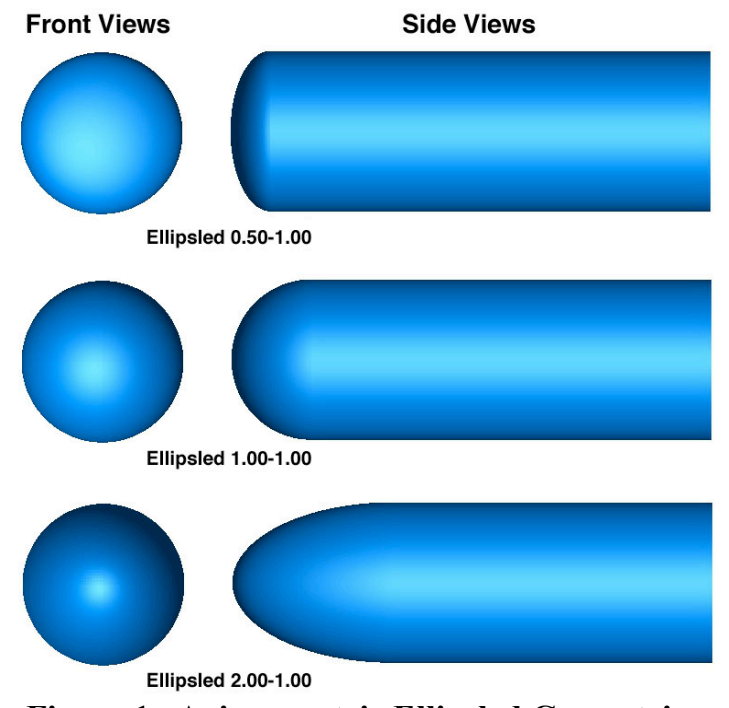

Figure 1. Axisymmetric Ellipsled Geometries

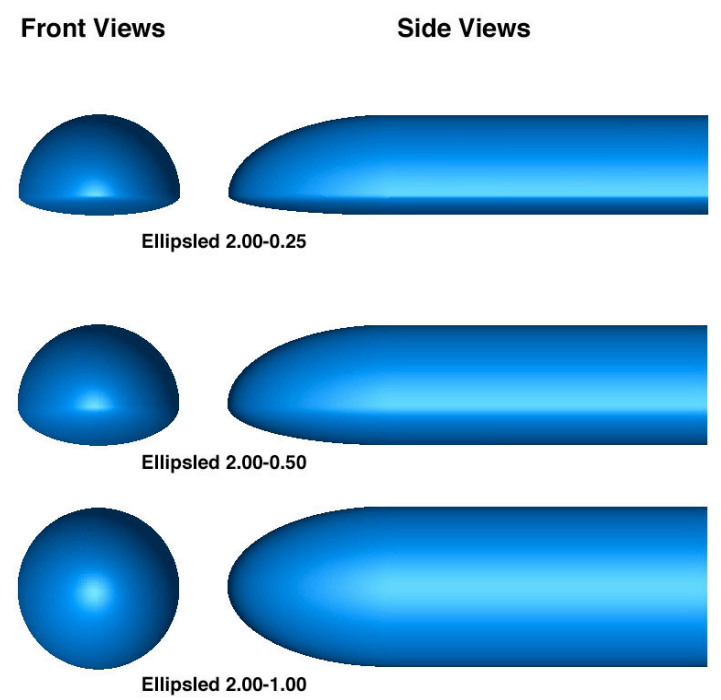

Figure 2. Flattened Ellipsled Geometries

TOP VIEW

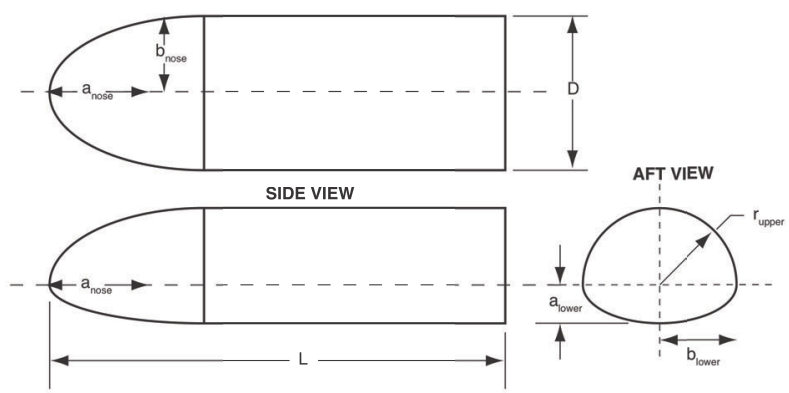

Figure 3. Ellipsled Geometry Definition

Table 1. Ellipsled Geometry Parameters

\begin{tabular}{cccccccccc}
\hline Geometry & $\begin{array}{c}\mathbf{L} \\
\text { (in) }\end{array}$ & $\begin{array}{c}\mathbf{D} \\
\text { (in) }\end{array}$ & $\begin{array}{c}\mathbf{a}_{\text {nose }} \\
\text { (in) }\end{array}$ & $\begin{array}{c}\mathbf{b}_{\text {nose }} \\
\text { (in) }\end{array}$ & $\mathbf{a}_{\text {nose }} / \mathbf{b}_{\text {nose }}$ & $\begin{array}{c}\mathbf{r}_{\text {upper }} \\
\text { (in) }\end{array}$ & $\begin{array}{c}\mathbf{a}_{\text {lower }} \\
\text { (in) }\end{array}$ & $\begin{array}{c}\mathbf{b}_{\text {lower }} \\
\text { (in) }\end{array}$ & $\mathbf{a}_{\text {lower }} / \mathbf{b}_{\text {lower }}$ \\
\hline Ellipsled-0.50-1.00 & 12.00 & 4.00 & 1.00 & 2.00 & 0.50 & 2.00 & 2.00 & 2.00 & 1.00 \\
Ellipsled-1.00-1.00 & 12.00 & 4.00 & 2.00 & 2.00 & 1.00 & 2.00 & 2.00 & 2.00 & 1.00 \\
Ellipsled-2.00-1.00 & 12.00 & 4.00 & 4.00 & 2.00 & 2.00 & 2.00 & 2.00 & 2.00 & 1.00 \\
Ellipsled-2.00-0.25 & 12.00 & 4.00 & 4.00 & 2.00 & 2.00 & 2.00 & 0.50 & 2.00 & 0.25 \\
Ellipsled-2.00-0.50 & 12.00 & 4.00 & 4.00 & 2.00 & 2.00 & 2.00 & 1.00 & 2.00 & 0.50 \\
\hline
\end{tabular}

\section{Dual-Use Hammerhead Biconic Shroud Geometries}

The biconic shroud family is based on a proposed dual-use "Hammerhead" shroud geometry for the Ares V heavy-lifter (Refs. 8, 9). Although the Ares V program has been cancelled, the general concept is applicable to any launch vehicle shroud. The shroud would be used during both ascent from Earth and entry/aerocapture at the destination. Three parametric geometries were developed for testing based on the Hammerhead biconic concept. Nose radius was the primary geometric variation, with the length of the first cone and angle of the second cone then being varied to fit the geometric constraints of a constant first-cone angle and constant second-cone length. The rationale for these constraints was to minimize changes to the internal volume of the vehicle, which is a function mainly of the geometry of the second cone and cylindrical third section. These geometries are shown in Figure 5 and the geometric parameters are defined in Figure 6 and listed in Table 2. 


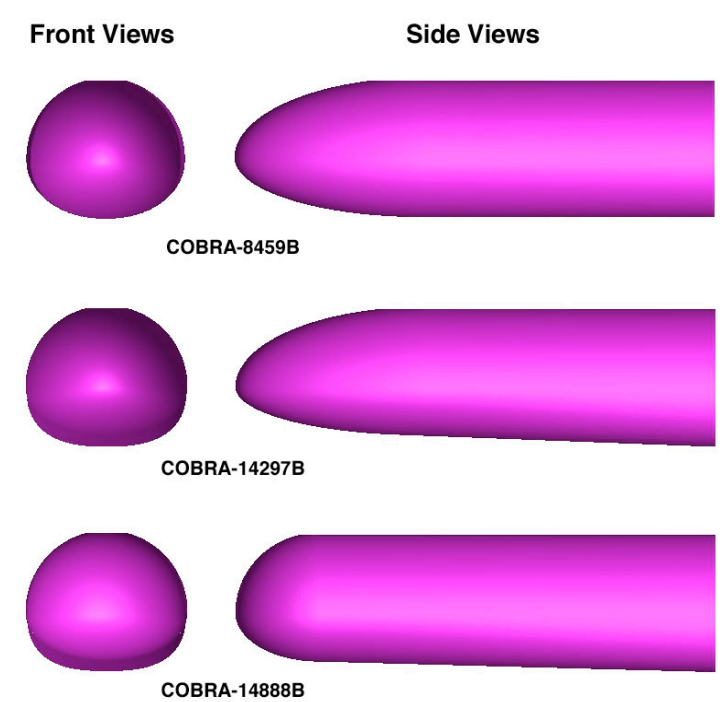

Figure 4. COBRA Geometries

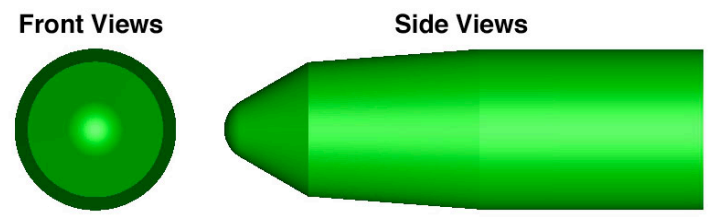

HAMMERHEAD-Sharp

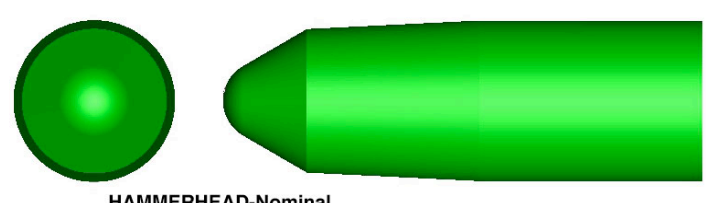

HAMMERHEAD-Nominal

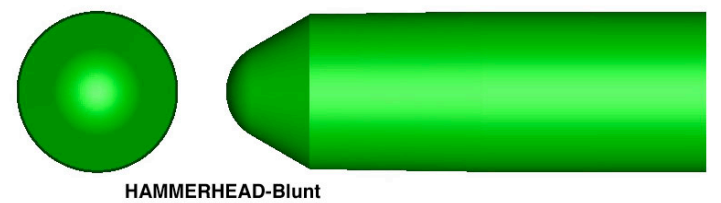

Figure 5. Hammerhead Biconic Geometries

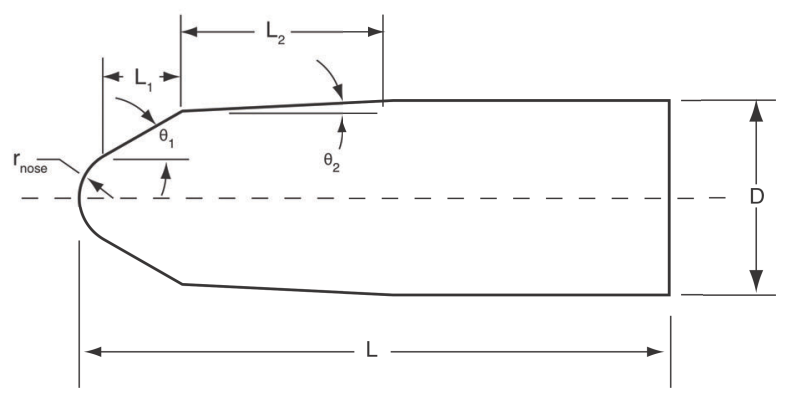

Figure 6. HAMMERHEAD Geometry Dimensions

Table 2. HAMMERHEAD Geometry Parameters

\begin{tabular}{lccccccc}
\hline \multicolumn{1}{c}{ Geometry } & $\mathbf{L}$ & $\begin{array}{c}\mathbf{D} \\
\text { (in.) }\end{array}$ & $\begin{array}{c}\mathbf{r}_{\text {nose }} \\
\text { (in.) }\end{array}$ & $\begin{array}{c}\boldsymbol{\theta}_{\mathbf{1}} \\
\text { (deg) }\end{array}$ & $\begin{array}{c}\mathbf{L}_{\mathbf{1}} \\
\text { (in.) }\end{array}$ & $\begin{array}{c}\boldsymbol{\theta}_{\mathbf{2}} \\
\text { (deg) }\end{array}$ & $\begin{array}{c}\mathbf{L}_{\mathbf{2}} \\
\text { (in.) }\end{array}$ \\
\hline Hammerhead-Sharp & 12.000 & 4.000 & 0.8000 & 30.0000 & 1.7000 & 4.3333 & 4.2981 \\
Hammerhead-Nominal & 12.000 & 4.000 & 1.0000 & 30.0000 & 1.6000 & 2.8000 & 4.2981 \\
Hammerhead-Blunt & 12.000 & 4.000 & 1.2500 & 30.0000 & 1.4750 & 0.8781 & 4.2981 \\
\hline
\end{tabular}

\section{Comparison of Aerodynamic Performance}

In order to obtain a first-order understanding of the aerodynamics of the various configurations, a Modified Newtonian analysis was performed. According to Modified Newtonian theory, the aerodynamics of a vehicle travelling at hypersonic speed can be approximated by integration of the pressure coefficient, $C_{p}$, over the surface of the vehicle, where $C_{p}$ is defined as:

$$
C_{p}=C_{p, \max } \cos ^{2} \theta
$$

The maximum pressure coefficient, $C_{p, \max }$, is the value obtained for a given free stream Mach number and specific heat ratio (for this case, $M_{\infty}=30$ and $\gamma=1.25$ were assumed) using the perfect-gas, normal shock relations. $\theta$ is the angle between the local surface normal at a point on the body and the free stream velocity vector. For computations of force and moment coefficients from the $C_{p}$ distributions, reference dimensions of $L=30 \mathrm{~m}$ and $S=78.54 \mathrm{~m}^{2}$ (based on the area of a circular $10 \mathrm{~m}$ diam. base) were used for all geometries.

The figures-of-merit for the aerodynamic analysis were the lift-to-drag ratio $(L / D)$ and the reduced (mass-less) ballistic coefficient, $\beta / m$, where: 


$$
\beta=\frac{m}{C_{D} S}
$$

The optimum aerodynamic performance is obtained for the highest L/D (for maneuverability and precision landing) at the lowest $\beta$ (for greatest vehicle payload). These figures-of-merit are displayed in terms of L/D vs. angle-of-attack and L/D vs. reduced ballistic coefficient in Figure 7 - Figure 8 for the Ellipsled geometries, Figure 9 - Figure 10 for the COBRA geometries, and Figure 11 - Figure 12 for the Hammerhead geometries. The range of interest for Mid-L/D performance (approximately 0.4 to 0.8 ) is highlighted in the figures. Additionally, for each geometry, the angle of attack and reduced ballistic coefficient are tabulated for L/D Table 3 . In terms of these parameters, the flattened Ellipsled-2.00-0.25 produces the best performance and the axisymmetric Ellipsled-0.501.00 produces the worst performance. All geometries can meet the required $L / D$ range within angles-of-attack of 30-deg to 70-deg except the Ellipsled-0.50-1.00 and Ellipsled-0.50-1.00. However, in a complete mission system analysis, other constraints would also be considered, e.g.: convective and shock-layer radiative heating; aerodynamic stability; internal payload layout and packaging; vehicle structural strength and manufacturability; etc.

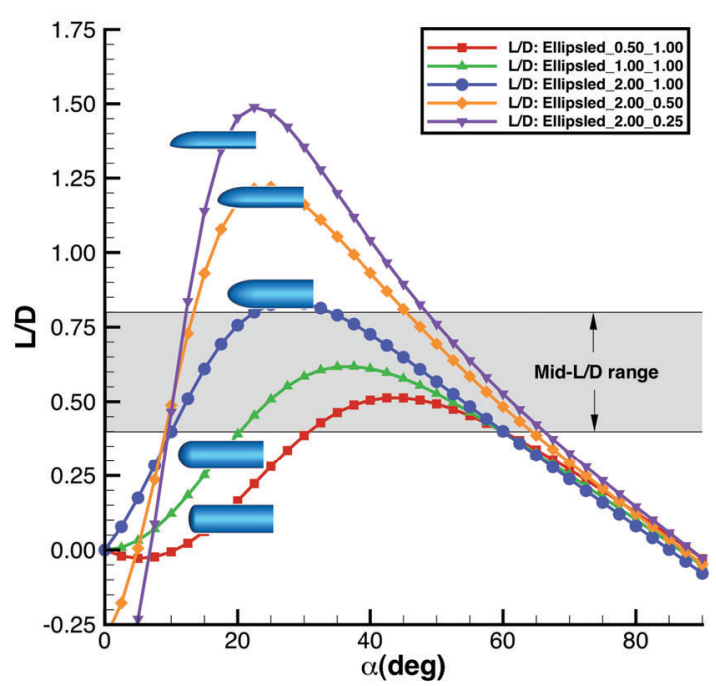

Figure 7. Ellipsled $L / D$ vs. Angle-of-Attack

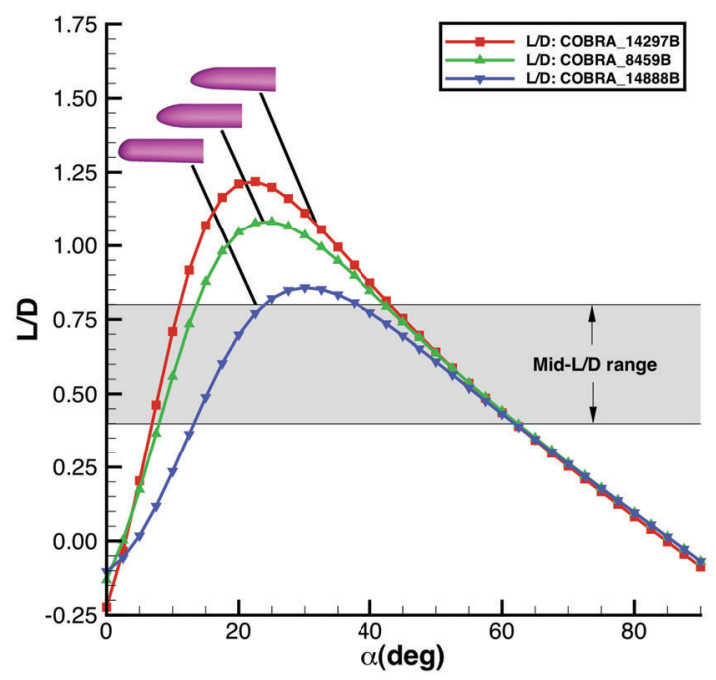

Figure 9. COBRA $L / D$ vs. Angle-of-Attack

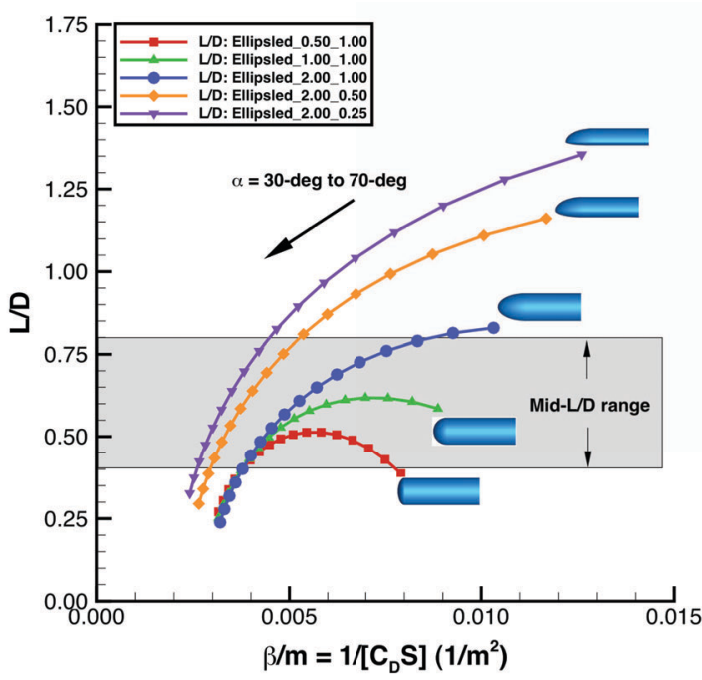

Figure 8. Ellipsled $L / D$ vs. Reduced Ballistic Coefficient

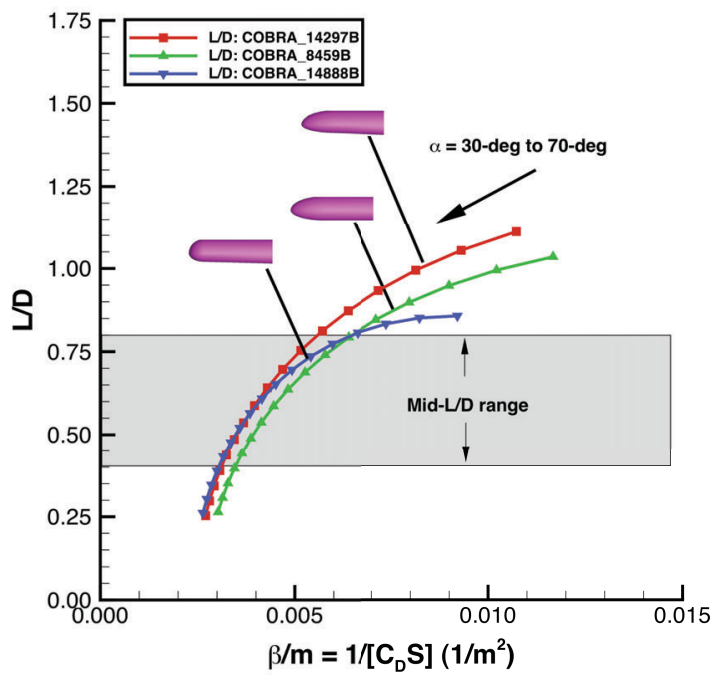

Figure 10. COBRA $L / D$ vs. Reduced Ballistic Coefficient

5

American Institute of Aeronautics and Astronautics 


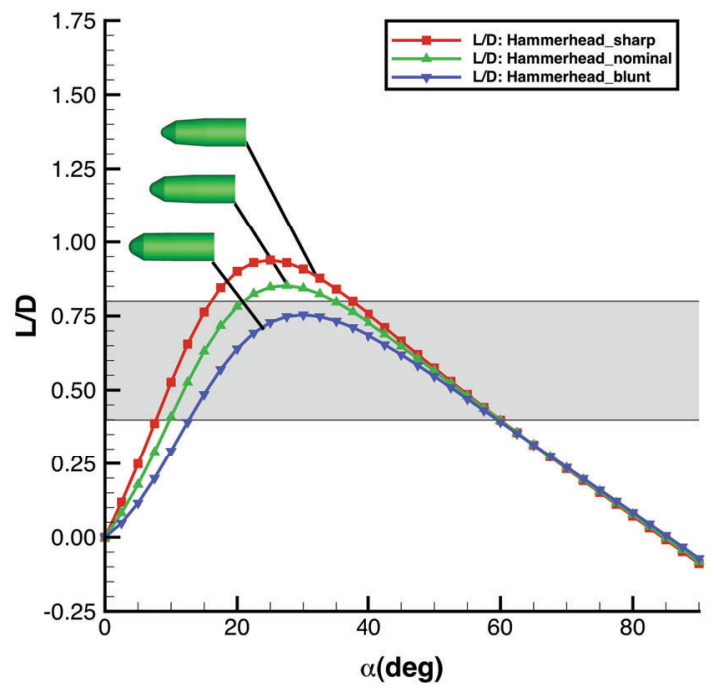

Figure 11. Hammerhead $L / D$ vs. Angle-ofAttack

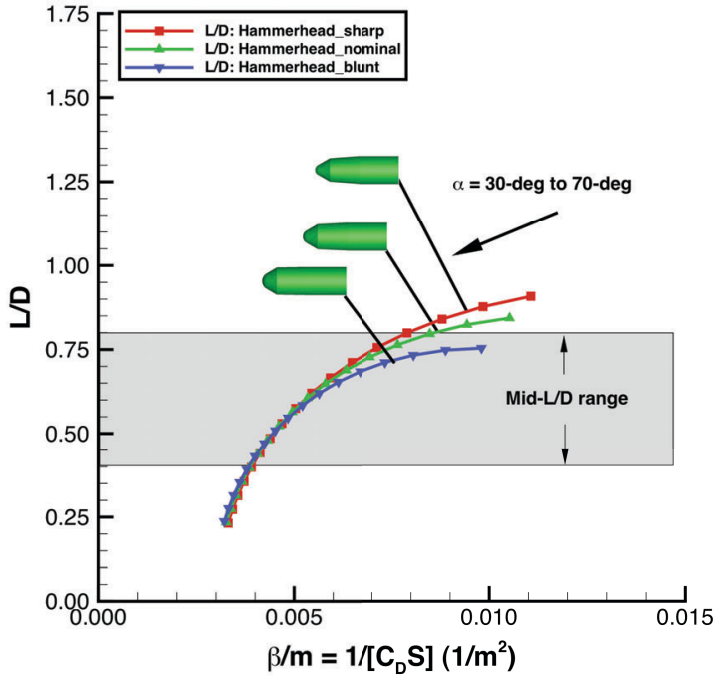

Figure 12. Hammerhead $L / D$ vs. Reduced Ballistic Coefficient

Table 3. Aerodynamic Performance Estimates

\begin{tabular}{|c|c|c|c|c|}
\hline \multirow[t]{2}{*}{ Geometry } & \multicolumn{2}{|c|}{$L / D=0.4$} & \multicolumn{2}{|c|}{$L / D=0.8$} \\
\hline & $\alpha(\operatorname{deg})$ & $\beta / m\left(1 / m^{2}\right)$ & $\alpha(\mathrm{deg})$ & $\beta / \mathrm{m}\left(1 / \mathrm{m}^{2}\right)$ \\
\hline Ellipsled-0.50-1.00 & 60.2 & 0.0038 & N/A & $\mathrm{N} / \mathrm{A}$ \\
\hline Ellipsled-1.00-1.00 & 60.2 & 0.0037 & $\mathrm{~N} / \mathrm{A}$ & N/A \\
\hline Ellipsled-2.00-1.00 & 60.2 & 0.0038 & 34.8 & 0.0084 \\
\hline Ellipsled-2.00-0.50 & 64.8 & 0.0029 & 45.8 & 0.0052 \\
\hline Ellipsled-2.00-0.25 & 67.0 & 0.0026 & 49.0 & 0.0044 \\
\hline COBRA-8459B & 62.1 & 0.0035 & 42.5 & 0.0064 \\
\hline COBRA-14297B & 62.1 & 0.0031 & 43.9 & 0.0054 \\
\hline COBRA-14888B & 62.1 & 0.0030 & 38.7 & 0.0063 \\
\hline Hammerhead-Blunt & 60.0 & 0.0039 & $\mathrm{~N} / \mathrm{A}$ & $\mathrm{N} / \mathrm{A}$ \\
\hline Hammerhead-Nominal & 60.0 & 0.0038 & 35.3 & 0.0084 \\
\hline Hammerhead-Sharp & 60.0 & 0.0037 & 38.2 & 0.0077 \\
\hline
\end{tabular}

\section{Facility and Test Technique}

\section{A. Description of NASA LaRC 20-Inch Mach 6 Air Tunnel}

The NASA Langley Research Center 20-Inch Mach 6 Air Tunnel (Figure 13) is a blow-down facility in which heated, dried, and filtered air is used as the test gas. A detailed description of this facility can be found in Ref. 10 . The tunnel has a two-dimensional contoured nozzle that opens into a 20.5 in. $\times 20.0$ in. $(0.52 \mathrm{~m} \times 0.508 \mathrm{~m})$ test section. The tunnel is equipped with a bottom-mounted injection system that can transfer a model from the sheltered model box to the tunnel centerline in less than $0.5 \mathrm{sec}$. Run times of up to 15 minutes are possible in this facility, although for the current aeroheating study, run times of only a few seconds were required. The nominal reservoir conditions of this facility produce perfect-gas free-stream flows with Mach numbers between 5.8 and 6.1 and unit Reynolds numbers of $0.5 \times 10^{6} / \mathrm{ft}$ to $8.3 \times 10^{6} / \mathrm{ft}\left(1.64 \times 10^{6} / \mathrm{m}\right.$ to $\left.27.2 \times 10^{6} / \mathrm{m}\right)$. Conditions for the current test series are listed in Table 4. The heat-transfer values listed in this table are based on Fay-Riddell calculations for a reference 2 -in. radius hemisphere at cold-wall $(300 \mathrm{~K})$ conditions. Five different Reynolds number points were employed with the intent of generating a range of laminar, transitional, and turbulent data on each geometry. All runs were performed at a 40-deg angle-of-attack. 


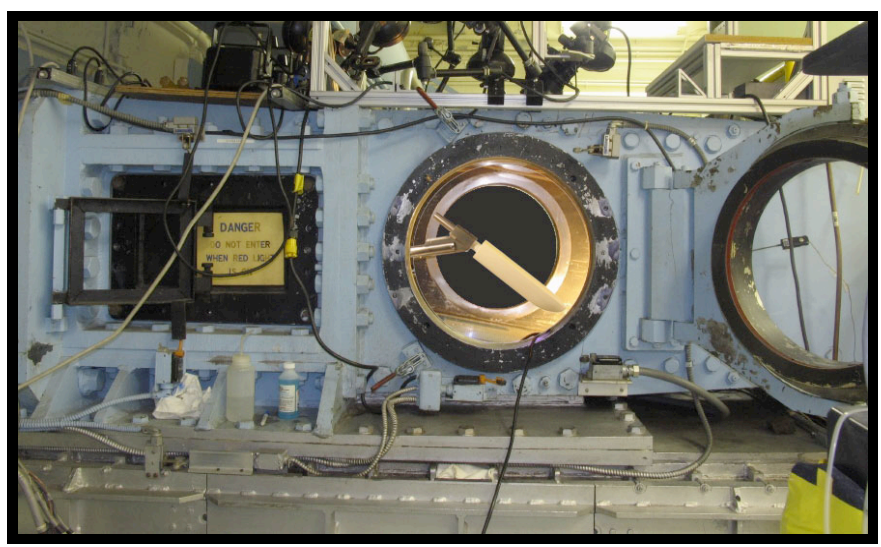

Figure 13. LaRC 20-Inch Mach 6 Air Tunnel

Table 4. Nominal Conditions for LaRC 20-Inch Mach 6 Air Tunnel Test 6966

\begin{tabular}{ccccccccccc}
\hline $\begin{array}{c}\boldsymbol{\alpha} \\
(\mathbf{d e g})\end{array}$ & $\begin{array}{c}\mathbf{R e}_{\infty} \\
(\mathbf{1} / \mathbf{f t})\end{array}$ & $\begin{array}{c}\mathbf{R e}_{\infty} \\
(\mathbf{1} / \mathbf{m})\end{array}$ & $\mathbf{M}_{\infty}$ & $\begin{array}{c}\mathbf{P}_{\infty} \\
(\mathbf{P a})\end{array}$ & $\begin{array}{c}\mathbf{T}_{\infty} \\
(\mathbf{K})\end{array}$ & $\begin{array}{c}\boldsymbol{\rho}_{\infty} \\
\left(\mathbf{k g} / \mathbf{m}^{3}\right)\end{array}$ & $\begin{array}{c}\mathbf{U}_{\infty} \\
(\mathbf{m} / \mathbf{s})\end{array}$ & $\begin{array}{c}\mathbf{H}_{\mathbf{0}}-\mathbf{H}_{\mathbf{3 0 0 K}} \\
(\mathbf{J} / \mathbf{k g})\end{array}$ & $\begin{array}{c}\mathbf{h}_{\mathrm{FR}} \\
\left(\mathbf{k g} / \mathbf{m}^{2} / \mathbf{s}\right)\end{array}$ & $\begin{array}{c}\mathbf{q}_{\mathrm{FR}} \\
(\mathbf{W} / \mathbf{c m})^{2}\end{array}$ \\
\hline 40 & $3.01 \times 10^{6}$ & $9.87 \times 10^{6}$ & 5.97 & 687 & 54.8 & $4.380 \times 10^{-2}$ & 882.2 & $1.431 \times 10^{5}$ & $2.336 \times 10^{-1}$ & 3.342 \\
40 & $4.79 \times 10^{6}$ & $1.57 \times 10^{7}$ & 5.99 & 1129 & 56.1 & $7.034 \times 10^{-2}$ & 895.0 & $1.556 \times 10^{5}$ & $3.013 \times 10^{-1}$ & 4.688 \\
40 & $6.84 \times 10^{6}$ & $2.24 \times 10^{7}$ & 6.02 & 1667 & 57.4 & $1.016 \times 10^{-1}$ & 908.0 & $1.686 \times 10^{5}$ & $3.685 \times 10^{-1}$ & 6.215 \\
40 & $7.58 \times 10^{6}$ & $2.49 \times 10^{7}$ & 6.02 & 1879 & 58.1 & $1.132 \times 10^{-1}$ & 913.8 & $1.746 \times 10^{5}$ & $3.921 \times 10^{-1}$ & 6.847 \\
40 & $8.33 \times 10^{6}$ & $2.73 \times 10^{7}$ & 6.03 & 2091 & 58.6 & $1.249 \times 10^{-1}$ & 918.2 & $1.792 \times 10^{5}$ & $4.172 \times 10^{-1}$ & 7.475
\end{tabular}

\section{B. Wind Tunnel Model Design and Data Acquisition}

Wind tunnel models for each of the Mid- $L / D$ geometries were slip-cast in silica-ceramic and coated with a thermographic phosphor compound as per the process discussed in Ref. 11. All models were 12-in. $(0.3048 \mathrm{~m})$ in length. Heating levels over the models were measured using the two-color, relative-intensity, global thermographic phosphor method (Refs. 12, 13). In this method, heat-transfer coefficients are determined by assuming a stepfunction in heat-transfer beginning at injection of the model into the tunnel, which corresponds to a parabolic temperature-time history. The model is illuminated by ultra-violet light sources that produce temperature-dependent fluorescence of the phosphor-coating and images of the model are taken in the tunnel before and during a run using a three-color, charge-coupled device camera. The IHEAT (Imaging for Hypersonic Experimental Aerothermodynamic Testing) code uses calibrations to convert the intensity data from each image pixel to temperatures and then performs the heat-transfer computations. Heat-transfer distributions in IHEAT are determined in terms of the ratio $h / h_{\mathrm{FR}}$, where $h_{\mathrm{FR}}$ is the heat-transfer coefficient resulting from a Fay-Riddell computation (Ref. 14) for a reference hemisphere. These results are then converted to a laminar heating correlation parameter defined in terms of the Stanton and Reynolds numbers, $\operatorname{St} \times\left(\operatorname{Re}_{\infty, \mathrm{D}}\right)^{(1 / 2)}$, where:

$$
S t \times\left(\operatorname{Re}_{\infty, D}\right)^{(1 / 2)}=\frac{q_{w}}{\rho_{\infty} U_{\infty}\left(H_{0}-H_{w}\right)}\left(\frac{\rho_{\infty} U_{\infty} D}{\mu_{\infty}}\right)^{(1 / 2)}=\left(h / h_{F R}\right) \frac{h_{F R}}{\rho_{\infty} U_{\infty}}\left(\frac{\rho_{\infty} U_{\infty} D}{\mu_{\infty}}\right)^{(1 / 2)}
$$

The image data obtained from IHEAT are corrected for optical perspective effects and mapped to a threedimensional (3-D) surface model for that geometry. To accomplish this mapping, perspective transformations are first performed on the 3-D surface geometry until its 2-D projection matches that of the 2-D image data. The image data are then assigned transformed $(x, y, z)$ coordinates based on interpolation between the image and surface geometry, and then the transformation is inverted to obtain an orthographic 3-D heating distribution map.

The experimental uncertainty of the measured heating levels is estimated as the root-mean-square summation of the component uncertainties due to: the data acquisition method $( \pm 10 \%)$; flow quality and test-condition repeatability $( \pm 5 \%)$; and the accuracy of the $3 \mathrm{D}$ mapping process $( \pm 10 \%)$, which results in an overall value of 
$\pm 15 \%$. Experience with this technique indicates that these values are conservative, however this estimate does not include multi-dimensional conduction effects such as experienced in regions of high surface curvature or imaging errors due to poor lighting or viewing angle. These effects are generally only significant at sharp nose-tips (as on the flattened ellipsleds) or corners (as on the Hammerhead geometries at the junctions of the different segments) or on the sides of a model (which are tangent to the camera view angle).

\section{Computational Method}

Flow field predictions were performed using the LAURA (Langley Aerothermodynamic Upwind Relaxation Algorithm) code (Refs. 15, 16) to obtain heat-transfer rates for comparisons with the experimental data. LAURA is a three-dimensional, finite-volume solver that includes perfect-gas, equilibrium, and non-equilibrium chemistry models. In this study, the perfect-gas air model was used for the wind tunnel predictions. Free-stream conditions in the wind tunnel do not vary significantly from run to run, so the nominal conditions in Table 4 were used, with the wall temperature set to a constant $300 \mathrm{~K}$. The use of a constant wall temperature is acceptable because the heattransfer coefficient varies only very slightly over the range of wall temperatures produced in this facility. Cases for turbulent flow were computed using the Cebeci-Smith algebraic turbulence model (as per Ref. 17), which has been shown to give good comparisons to data from perfect-gas, attached flow conditions over smooth, blunt-body geometries (e.g. Ref. 18).

Structured, half-body, multi-block computational grids were generated for each configuration with 96 bodynormal cells, 128 circumferential cells and 128 - 160 stream-wise cells (depending on configuration) and singularity-free nose blocks. For computational speed and simplicity, the aft cap and wake of the geometry was not modeled, thus the end of the geometry was treated as an extrapolation outflow boundary. Grid adaption to the solution features was performed to align the grid outer boundary with the shock and to cluster cells near the surface to produce wall cell Reynolds numbers on the order of 1 .

Since the intent of this study was to obtain experimental data, not to optimize CFD methodology, grid resolution and topology refinement have not yet been considered beyond the original grids. As will be noted in later comparisons, the use of the extrapolation outflow boundary instead of a full-wake grid, and the lack of surface grid point clustering around some topology features (e.g. the junctions between the Hammerhead geometry sections) likely contributed to discrepancies between predictions and data in these regions.

\section{Results and Analysis}

\section{A. Global Aeroheating Data}

The 3-D mapped, global heating distributions are shown for each configuration at each of the test Reynolds numbers in Figure 14 - Figure 24 in terms of the laminar correlation parameter $S t \times\left(R e_{\infty, \mathrm{D}}\right)^{(1 / 2)}$. In each figure, the images are ordered from left to right in terms of increasing Reynolds number. Since this correlation parameter remains constant with Reynolds number for laminar flow, areas on each model where boundary-layer transition and turbulent flow occurs can be seen as changes in the heating patterns from figure to figure. In general, boundarylayer transition along the centerline was observed (at different Reynolds numbers) for all configurations except Ellipsled-2.00-1.00. Additionally, outboard cross-flow transition may have occurred on several of the configurations. Finally, on several of the geometries (Ellipsled-2.00-1.00, COBRA-8459B and COBRA-14297B), streaks near the nose may indicate transition due to slight imperfections in the surface coating or cumulative damage over the test program, rather than natural "smooth" OML transition; however these disturbances are quickly washed outboard and do not seem to affect the centerline transition.

\section{Ellipsled Configurations}

Ellipsled heating distributions are shown in Figure 14 - Figure 18. Boundary-layer transition along the model centerline was observed for all ellipsled configurations except the sharpest-nosed axisymmetric configuration Ellipsled-2.00-1.00. On the axisymmetric Ellipsled-1.00-1.00 and Ellipsled-2.00-1.00 configurations, "feathered" heating patterns of increasing strength with Reynolds number were produced outboard of the configuration oriented away from the centerline; these patterns are likely indicative of vortices from cross-flow transition. No such patterns were observed on the flattened ellipsled configurations. The greatest extent of fully-developed turbulent flow and highest levels of turbulent heating were produced on the axisymmetric Ellipsled-0.50-1.00 and flattened Ellipsled-2.00-0.25 configurations. Analysis of computed flow-field distributions revealed that an over-expansion and re-compression shock was produced on the Ellipsled-0.50-1.00 geometry immediately downstream of the nose/cylinder junction. This flow-field feature acts to promote transition sooner than would occur via the "natural, smooth-surface" sensitivity to increasing Reynolds number. 


\section{COBRA Configurations}

"COBRA" heating distributions are shown in Figure 19 - Figure 21. Some extent of centerline transitional and turbulent flow was observed for all configurations at the higher Reynolds numbers. However, with the exception of the highest Reynolds number COBRA-14297B case, the extent of transitional / turbulent flow and resulting turbulent heating were lower than the ellipsled configurations. This single case may have been an anomalous early transition produced by natural roughness due to the model casting and coating process or cumulative damage to the model phosphor coating since the transition onset front near the nose appears to be more wedge-like than planar. Also, faint outboard "feathering" patterns near the end of the COBRA-8459B geometry may indicate cross-flow transition.

\section{Hammerhead Configurations}

Hammerhead geometry heating distributions are shown in Figure 22 - Figure 24. The Hammerhead configurations produced more complex flow patterns than the other configurations due to discontinuities in the geometric slopes between the different segments and to the proximity of the stagnation point to the junction of the nose and first cone section. For the Hammerhead-sharp and Hammerhead-blunt configurations, boundary-layer transition occurred ahead of, or almost immediately downstream of, the junction of the first and second cone sections and rapidly evolved into fully-turbulent flow for all but the lowest two Reynolds numbers. In contrast, boundary-layer transition for the Hammerhead-nominal geometry did not occur until midway down the final cylindrical section. Additionally "feathering" patterns similar to those on the axisymmetric ellipsled were observed toward the outboard of the second cone section on the Hammerhead-nominal geometry which was indicative of cross-flow transition.

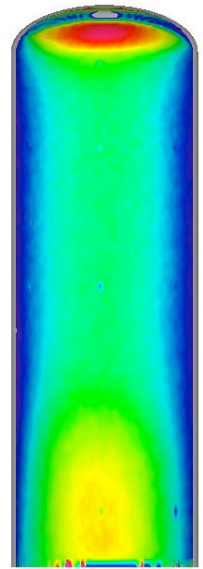

Run 39

$\operatorname{Re}_{\infty}=3.01 \times 10^{6} / \mathbf{f t}$

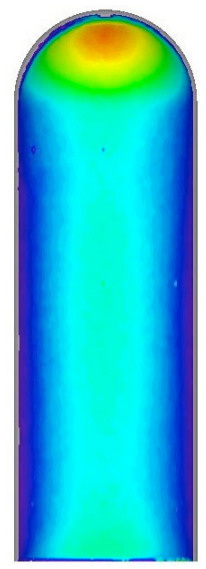

Run 33

$\operatorname{Re}_{\infty}=3.01 \times 10^{6} / \mathbf{f t}$

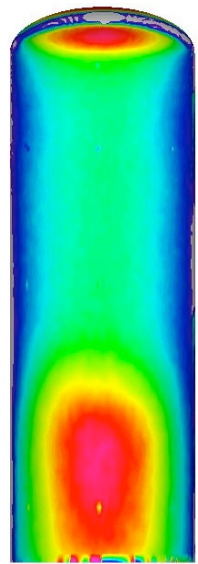

Run 40

$\operatorname{Re}_{\infty}=4.79 \times 10^{6} / \mathrm{ft}$

$\mathbf{R e}_{\infty}=\mathbf{6 . 8 4} \times 10^{6} / \mathrm{ft}$

Figure 14. Ellipsled-0.50-1.00

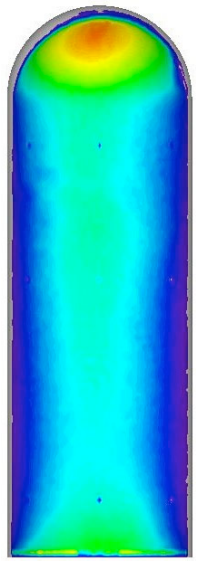

Run 9

$\operatorname{Re}_{\infty}=4.79 \times 10^{6} / \mathrm{ft}$

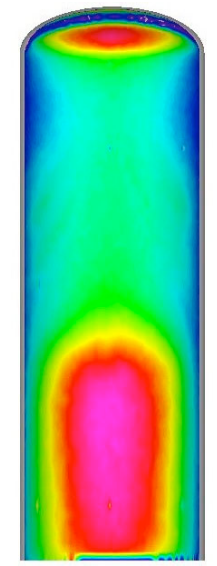

Run 41

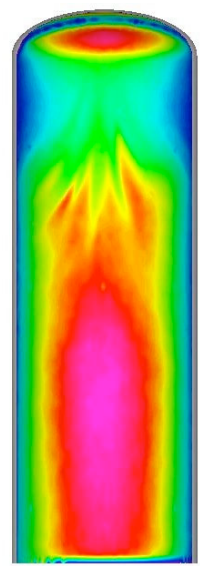

Run 42

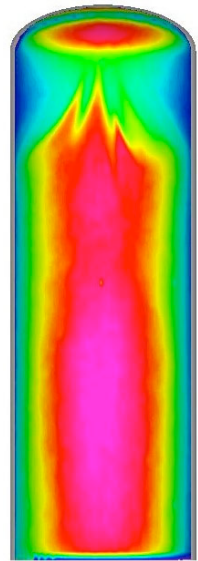

Run 43
$\operatorname{Re}_{\infty}=7.58 \times 10^{6} / \mathrm{ft}$

$\operatorname{Re}_{\infty}=8.33 \times 10^{6} / \mathrm{ft}$

$\operatorname{St} \times\left(\operatorname{Re}_{\infty, \mathrm{D}}\right)^{1 / 2}$

\begin{tabular}{|l|}
\hline \\
7 \\
\hline 6 \\
\hline 5 \\
4 \\
3 \\
2 \\
1 \\
\hline
\end{tabular}

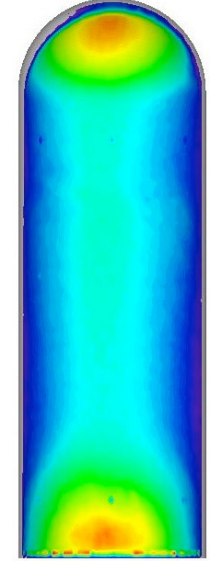

Run 8

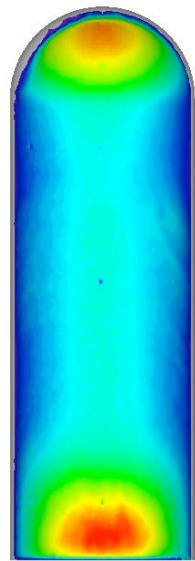

Run 32

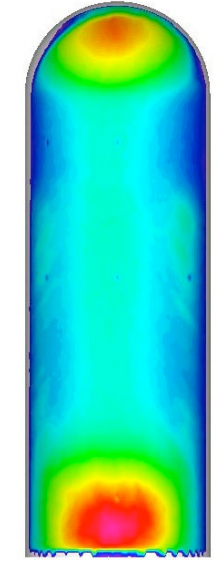

Run 10
$\operatorname{Re}_{\infty}=6.84 \times 10^{6} / \mathrm{ft} \quad \operatorname{Re}_{\infty}=7.58 \times 10^{6} / \mathrm{ft} \quad \operatorname{Re}_{\infty}=8.33 \times 10^{6} / \mathrm{ft}$
$\mathbf{S t} \times\left(\operatorname{Re}_{\infty, \mathbf{D}}\right)^{1 / 2}$

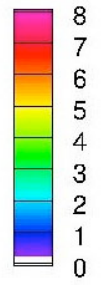

Figure 15. Ellipsled-1.00-1.00 Global Heating Distributions

9

American Institute of Aeronautics and Astronautics 


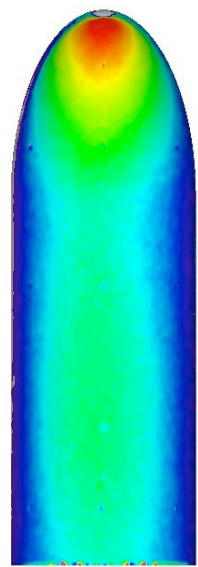

Run 12

$\operatorname{Re}_{\infty}=3.01 \times 10^{6} / \mathbf{f t}$

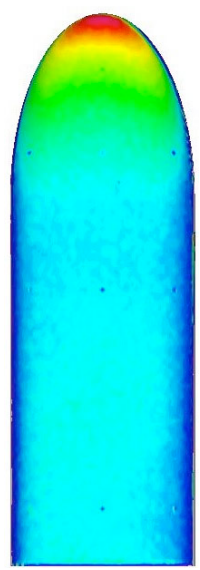

Run 27

$\operatorname{Re}_{\infty}=3.01 \times 10^{6} / \mathbf{f t}$

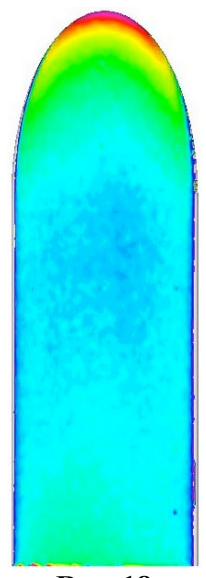

Run 18

$\operatorname{Re}_{\infty}=3.01 \times 10^{6} / \mathrm{ft}$

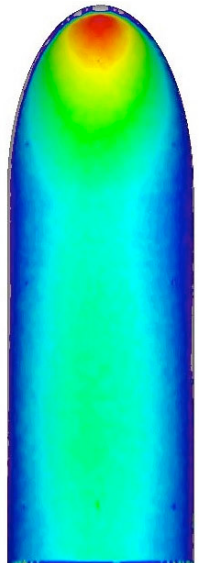

Run 17

$\operatorname{Re}_{\infty}=4.79 \times 10^{6} / \mathrm{ft}$

$\operatorname{Re}_{\infty}=6.84 \times 10^{6} / \mathrm{ft} \quad \operatorname{Re}_{\infty}=7.58 \times 10^{6} / \mathrm{ft}$

$\operatorname{Re}_{\infty}=7.58 \times 10^{6} / \mathrm{ft}$
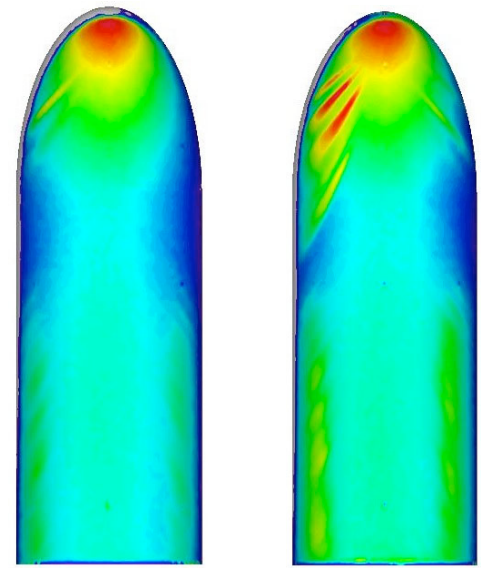

Run 15

$\operatorname{Re}_{\infty}=8.33 \times 10^{6} / \mathrm{ft}$

Figure 16. Ellipsled-2.00-1.00 Global Heating Distributions

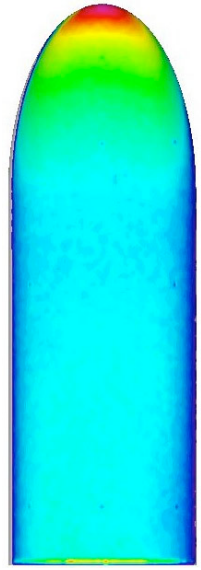

Run 25

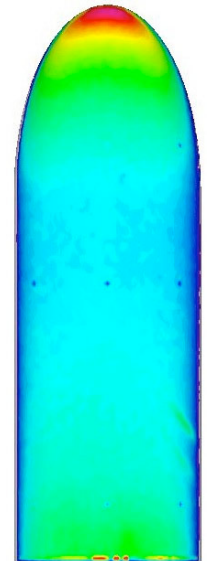

Run 26

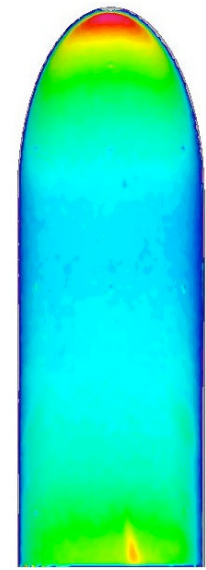

Run 28

$\operatorname{Re}_{\infty}=7.58 \times 10^{6} / \mathrm{ft}$

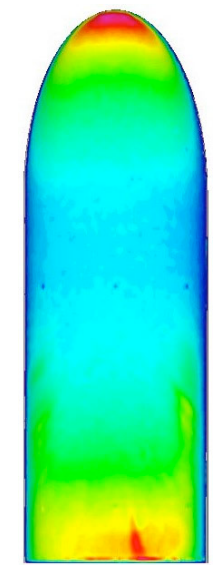

Run 29

$\operatorname{Re}_{\infty}=8.33 \times 10^{6} / \mathbf{f t}$

Figure 17. Ellipsled-2.00-0.50 Global Heating Distributions

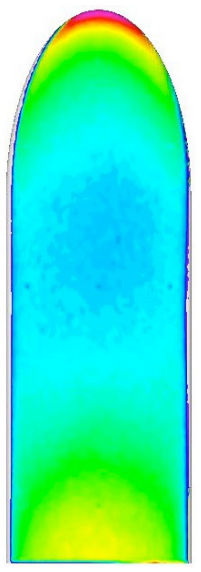

Run 19

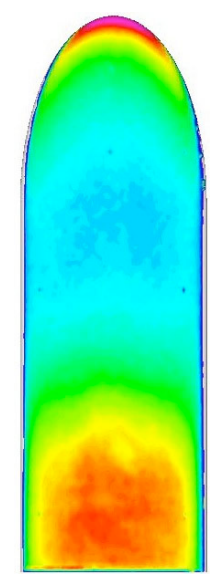

Run 20

$\operatorname{Re}_{\infty}=4.79 \times 10^{6} / \mathrm{ft} \quad \operatorname{Re}_{\infty}=6.84 \times 10^{6} / \mathrm{ft}$

Figure 18. Ellipsled-2.00-0.25 Global Heating Distributions

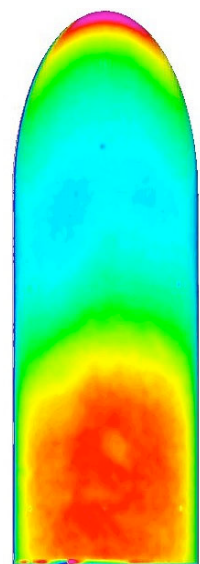

Run 23
Run 21

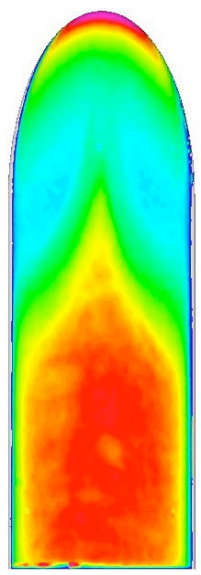

$\operatorname{Re}_{\infty}=8.33 \times 10^{6} / \mathrm{ft}$
$\operatorname{Re}_{\infty}=7.58 \times 10^{6} / \mathrm{ft}$
$\operatorname{St} \times\left(\operatorname{Re}_{\infty, \mathrm{D}}\right)^{1 / 2}$

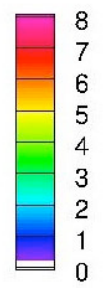

$\operatorname{St} \times\left(\operatorname{Re}_{\infty, \mathrm{D}}\right)^{1 / 2}$

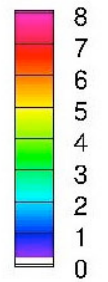

$\operatorname{St} \times\left(\operatorname{Re}_{\infty, \mathrm{D}}\right)^{1 / 2}$

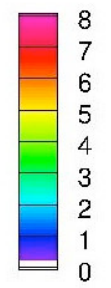




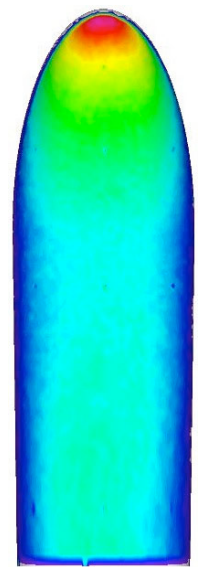

Run 54

$\operatorname{Re}_{\infty}=3.01 \times 10^{6} / \mathbf{f t}$

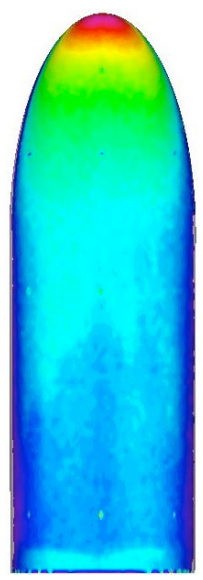

Run 45

$\operatorname{Re}_{\infty}=3.01 \times 10^{6} / \mathbf{f t}$

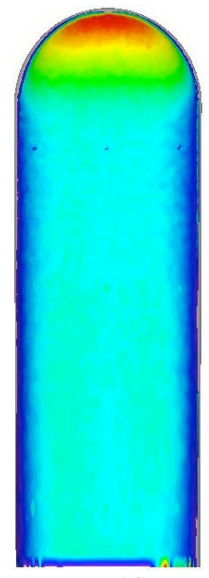

Run 105

$\operatorname{Re}_{\infty}=3.01 \times 10^{6} / \mathrm{ft}$

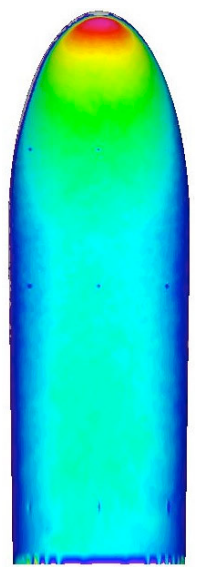

Run 81

$\operatorname{Re}_{\infty}=4.79 \times 10^{6} / \mathrm{ft}$

$\operatorname{Re}_{\infty}=6.84 \times 10^{6} / \mathrm{ft}$

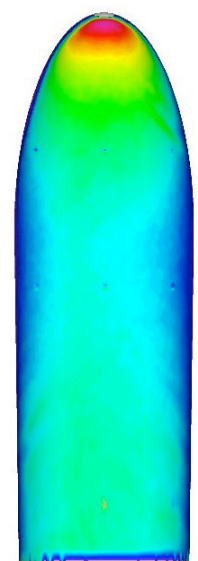

Run 83

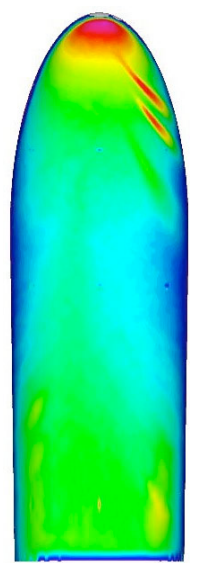

Run 85
$\operatorname{St} \times\left(\operatorname{Re}_{\infty, \mathrm{D}}\right)^{1 / 2}$

\begin{tabular}{|r|}
\hline \\
7 \\
6 \\
\hline 5 \\
4 \\
3 \\
2 \\
1 \\
0
\end{tabular}

Figure 19. COBRA-8459B Global Heating Distributions

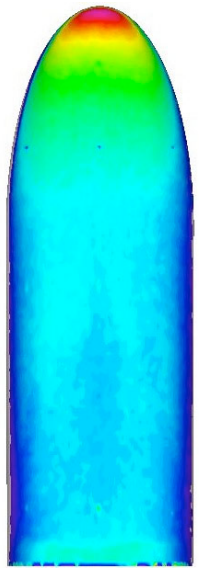

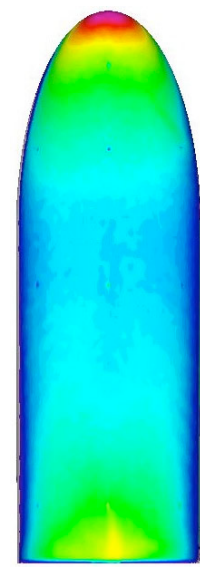

Run 110

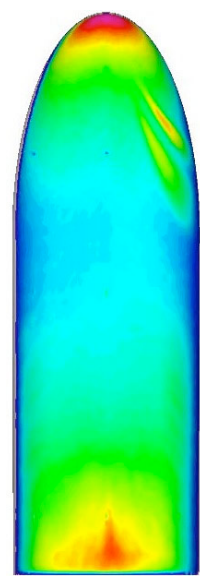

Run 111

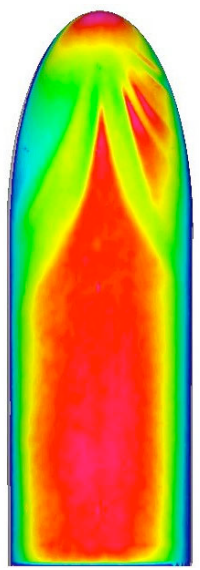

Run 50
$\operatorname{Re}_{\infty}=4.79 \times 10^{6} / \mathrm{ft} \quad \operatorname{Re}_{\infty}=6.84 \times 10^{6} / \mathrm{ft}$

$\operatorname{Re}_{\infty}=7.58 \times 10^{6} / \mathrm{ft}$

$\operatorname{Re}_{\infty}=8.33 \times 10^{6} / \mathrm{ft}$

Figure 20. COBRA-14297B Global Heating Distributions

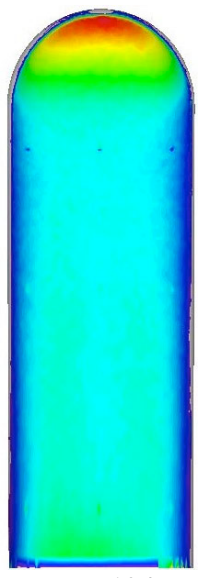

Run 104

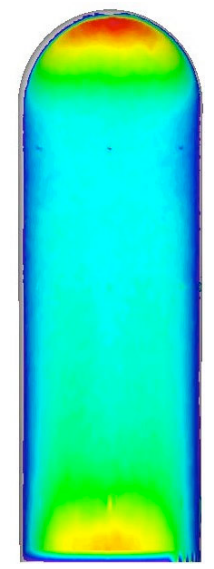

Run 107

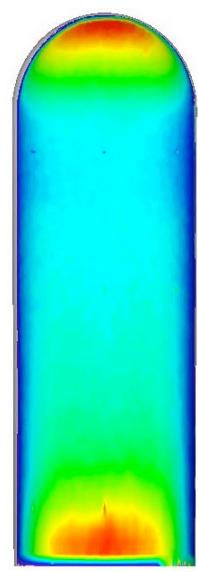

Run 108

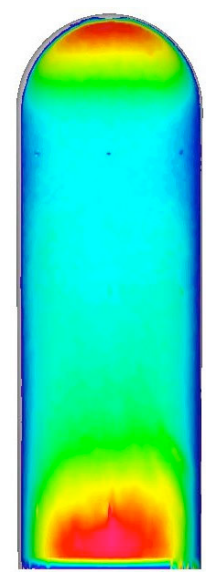

Run 109
$\operatorname{St} \times\left(\operatorname{Re}_{\infty, \mathrm{D}}\right)^{1 / 2}$

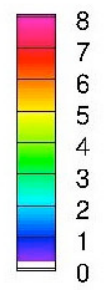

$\operatorname{St} \times\left(\operatorname{Re}_{\infty, \mathrm{D}}\right)^{1 / 2}$

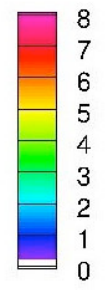

Figure 21. $C O B R A-14888 B$ Global Heating Distributions 


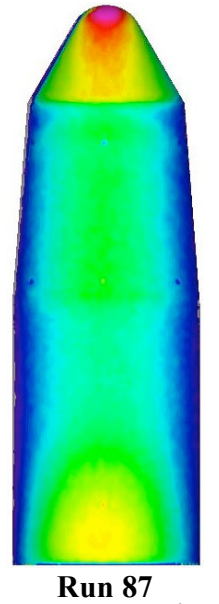

$\operatorname{Re}_{\infty}=3.01 \times 10^{6} / \mathbf{f t}$

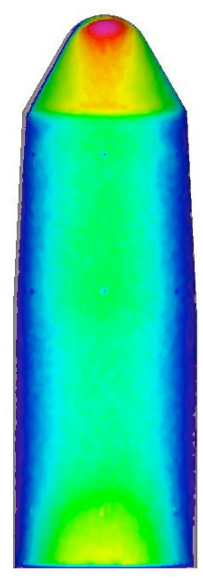

Run 95 $\operatorname{Re}_{\infty}=3.01 \times 106 / \mathbf{f t}$

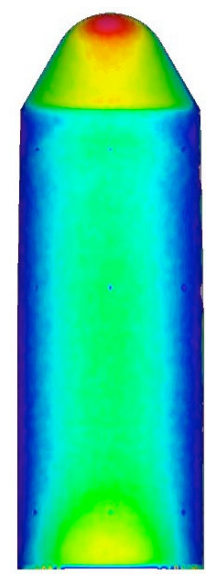

Run 100 $\operatorname{Re}_{\infty}=3.01 \times 10^{6} / \mathbf{f t}$

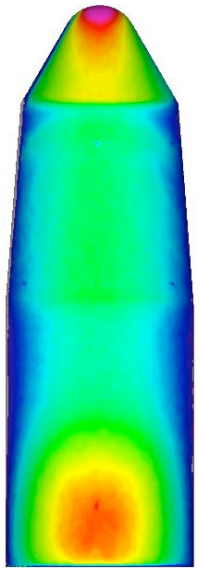

Run 86

$\operatorname{Re}_{\infty}=4.79 \times 10^{6} / \mathrm{ft}$

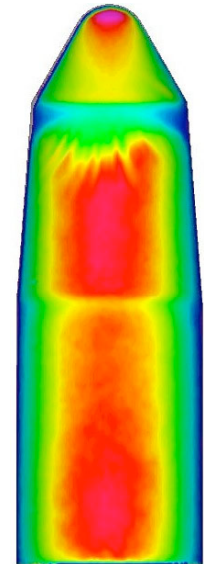

Run 89

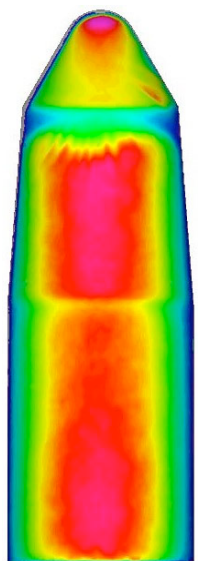

Run 90
$\operatorname{St} \times\left(\operatorname{Re}_{\infty, D}\right)^{1 / 2}$

\begin{tabular}{|r|}
\hline \\
\hline \\
\hline 6 \\
5 \\
\hline 4 \\
3 \\
2 \\
1 \\
\hline
\end{tabular}

Figure 22. Hammerhead-Sharp Global Heating Distributions

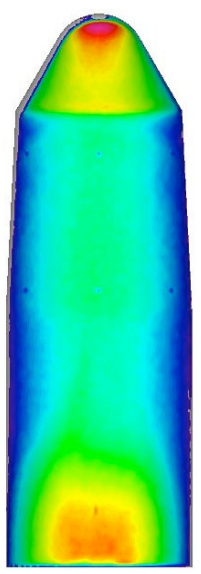

Run 93

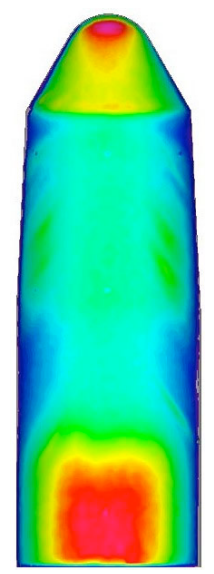

Run 96

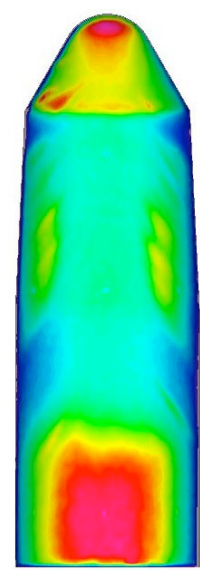

Run 97

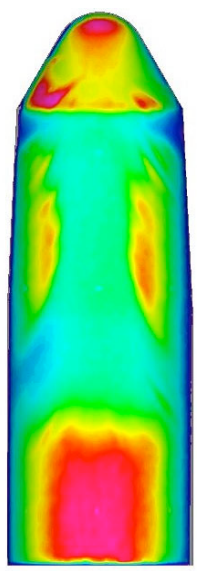

Run 98 $\operatorname{Re}_{\infty}=4.79 \times 10^{6} / \mathrm{ft} \quad \operatorname{Re}_{\infty}=6.84 \times 10^{6} / \mathrm{ft} \quad \operatorname{Re}_{\infty}=7.58 \times 10^{6} / \mathrm{ft} \quad \operatorname{Re}_{\infty}=8.33 \times 10^{6} / \mathrm{ft}$

Figure 23. Hammerhead-Nominal Global Heating Distributions

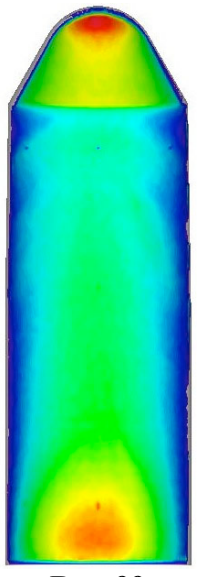

Run 99

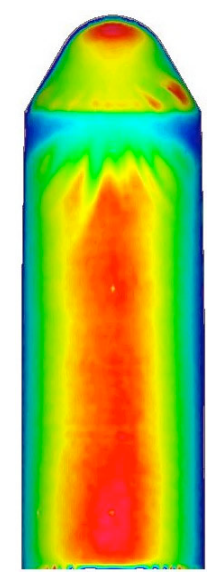

Run 101

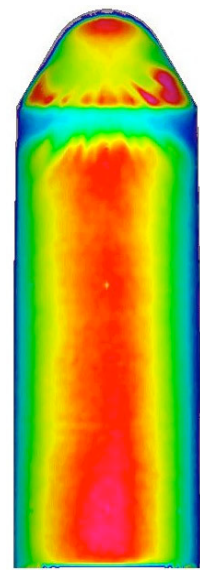

Run 102

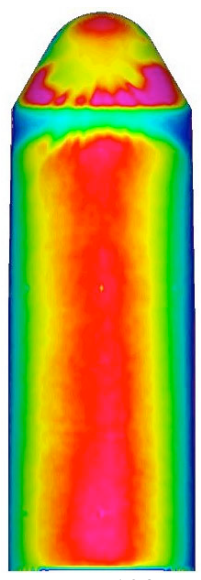

Run 103
$\operatorname{Re}_{\infty}=4.79 \times 10^{6} / \mathrm{ft} \quad \operatorname{Re}_{\infty}=6.84 \times 10^{6} / \mathrm{ft} \quad \operatorname{Re}_{\infty}=7.58 \times 10^{6} / \mathrm{ft} \quad \operatorname{Re}_{\infty}=8.33 \times 10^{6} / \mathrm{ft}$

Figure 24. Hammerhead-Blunt Global Heating Distributions
$\operatorname{St} \times\left(\operatorname{Re}_{\infty, D}\right)^{1 / 2}$

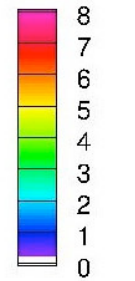

$\operatorname{St} \times\left(\operatorname{Re}_{\infty, D}\right)^{1 / 2}$

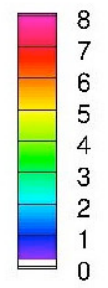




\section{B. Measured and Predicted Heating and Transition Characteristics}

Centerline comparisons between predicted and measured heating levels are presented in Figure 25 and Figure 26 in terms of the laminar correlation parameter $S t \times\left(R e_{\infty, \mathrm{D}}\right)^{(1 / 2)}$. Laminar predictions - which are Reynolds-number independent in this form - are shown for only the lowest Reynolds number condition. For Reynolds numbers where boundary-layer transition produced fully-turbulent flow on a given geometry, turbulent predictions are also shown. For these turbulent computations, the transition onset location and transition length was specified based on the wind tunnel data since the algebraic turbulent model employed does not provide a priori estimates for these properties.

Laminar data and predictions generally agreed to well within the experimental uncertainty. The only significant exception occurred on the Hammerhead geometries at the junction of the two cone-sections. Predictions were much lower than measurements downstream of this location, most likely due to insufficient surface-grid clustering at this discontinuity in the geometry.

Comparisons between turbulent predictions and transitional/turbulent data were more complex. Because the algebraic turbulence model in LAURA does not predict transition onset or the length of the transition region to fully-turbulent flow, these parameters were specified for the Dhawan-Narashima transition formulation (Ref. 19) in LAURA to match the observed data. However, while the transition onset location could be specified fairly accurately, the transition regime length and distribution were more difficult to match within the limits of this model. Thus differences greater than the experimental uncertainty were produced both within and downstream of the transition region. However, the comparisons were much better for the cases where a significant length of fullyturbulent flow was produced, notably on the Ellipsled-2.00-0.25, COBRA 142970B, Hammerhead-Blunt and Hammerhead-Sharp geometries at the higher Reynolds numbers. These observations pertain only to the centerline of the geometries, where stream-wise transition onset was dominant. No attempt was made to match the cross-flow transition patterns that were noted on several of the configurations.

In order to make a better assessment of the accuracy of the Cebeci-Smith turbulence model absent the effects of transition region distribution and cross-flow, an array of boundary-layer trips was employed on several of the geometries to force instantaneous, stream-wise transition. The arrays consisted of nine, $0.05 \times 0.05$ in. square, 0.0035 -in height trips spaced span-wise across the model at $x / L$ stations of $0.10,0.25$, or 0.50 and aligned 45 -deg (corner forward) towards the flow. These data and comparisons are shown in Figure 27. With the exception of the Ellipsled-1.00-1.00 case with trips at $x / L=0.1$, the predictions and data were in close agreement. For this anomalous case, it is possible that the placement of the trips on the curved nose section caused flow separation that disturbed the outer, inviscid flow structure.

Finally, to assess the heating environments between the geometries, measured heating levels at the nose stagnation point and at the max heating point on the body (whether laminar, transitional or turbulent) downstream of the nose were determined from the data. Also, the predicted, laminar heating level at the max measured body point were taken from the predictions and ratios of measured to predicted-laminar heating levels were computed. These parameters are listed in Table 5. The highest stagnation point heating was produced on the Hammerhead-Sharp configuration. The highest turbulent heating was produced on the Ellipsled-0.50-1.00 geometry, while the highest turbulent heating augmentation factor relative to laminar levels was produced on the Ellipsled-2.00-0.25 geometry. 

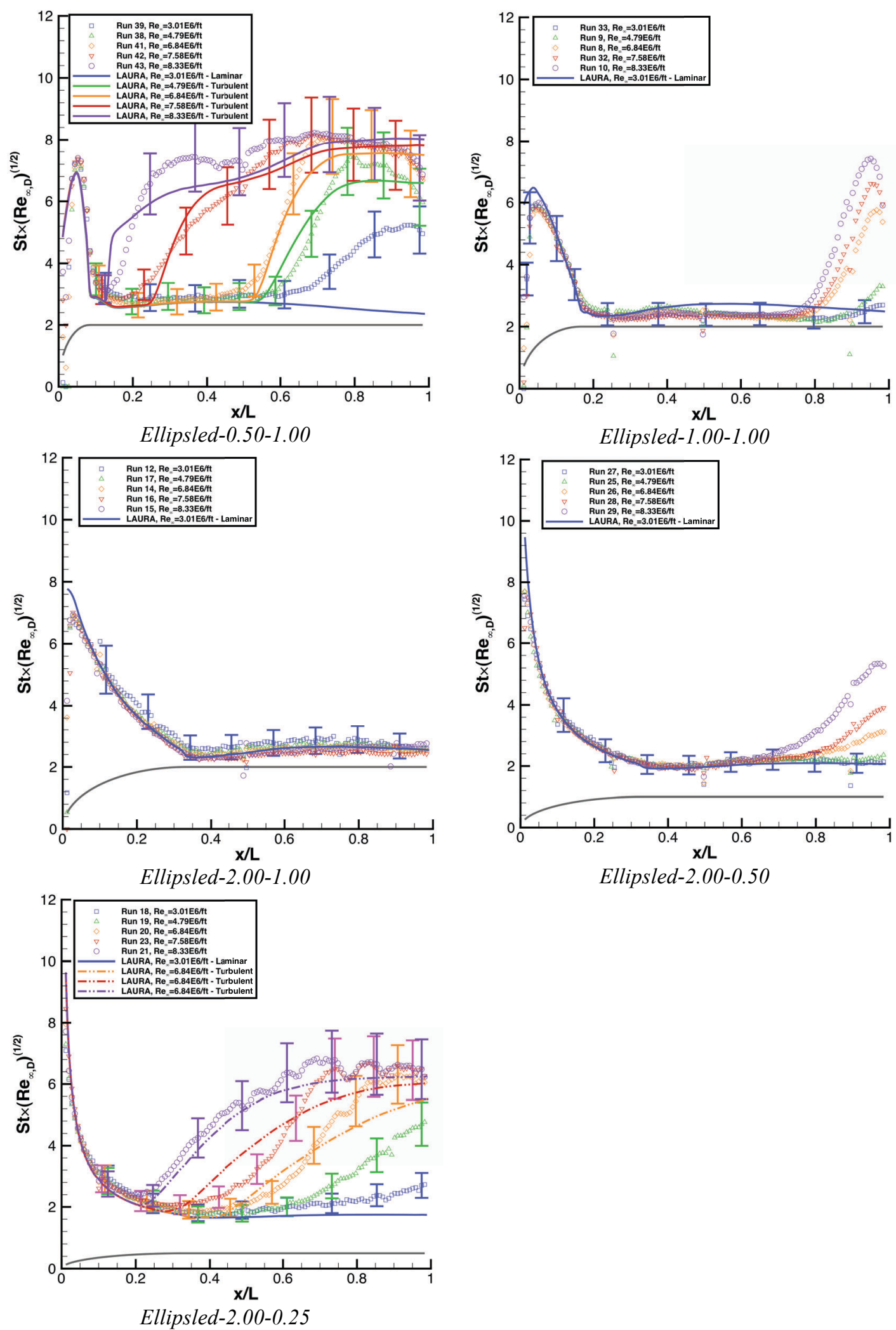

Figure 25. Centerline Heating Comparisons for Ellipsled Configurations

14

American Institute of Aeronautics and Astronautics 

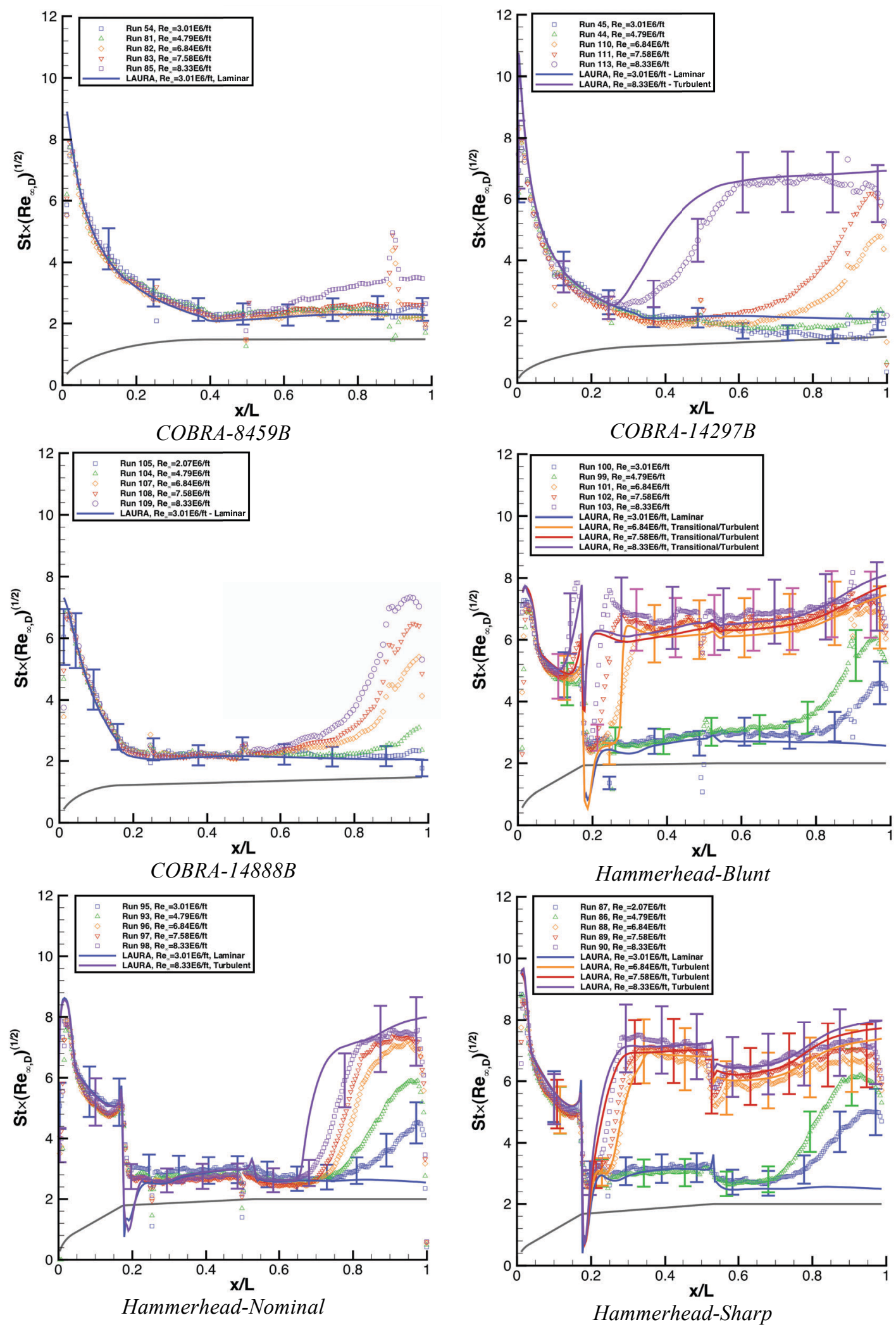

Figure 26. Centerline Heating Comparisons for COBRA and Hammerhead Configurations

15

American Institute of Aeronautics and Astronautics 


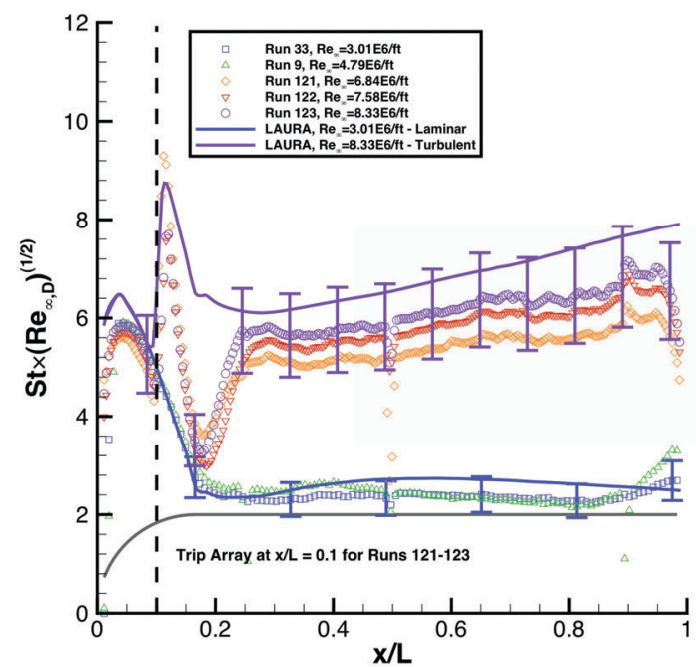

Ellipsled-1.00-1.00 with trips at $x / L=0.10$

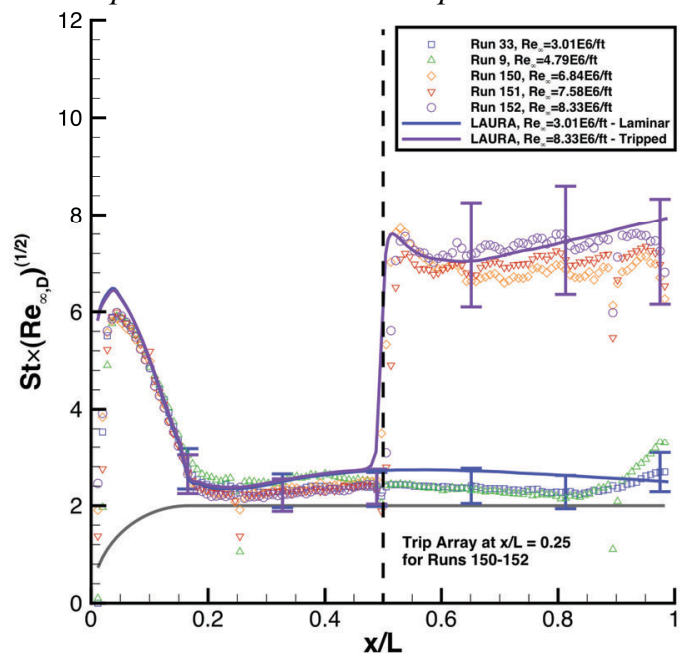

Ellipsled-1.00-1.00 with trips at $x / L=0.50$

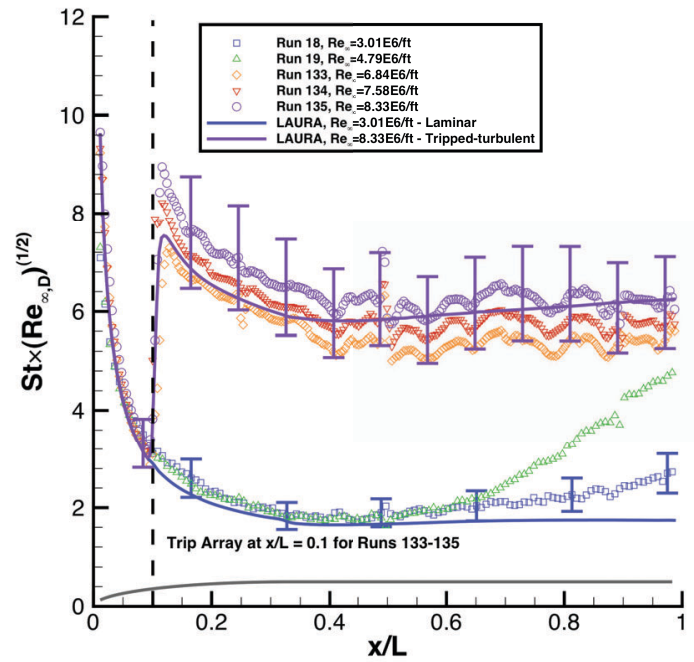

Ellipsled-2.00-0.25 with trips at $x / L=0.10$

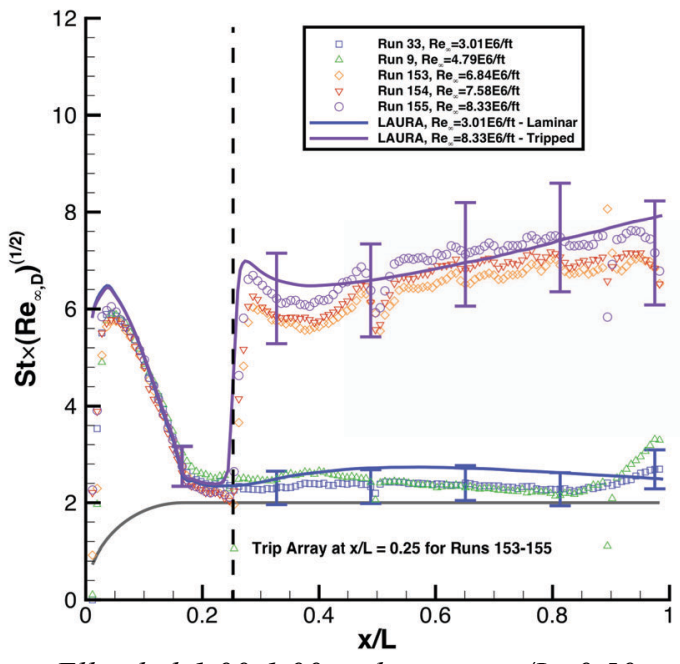

Ellipsled-1.00-1.00 with trips at $x / L=0.50$

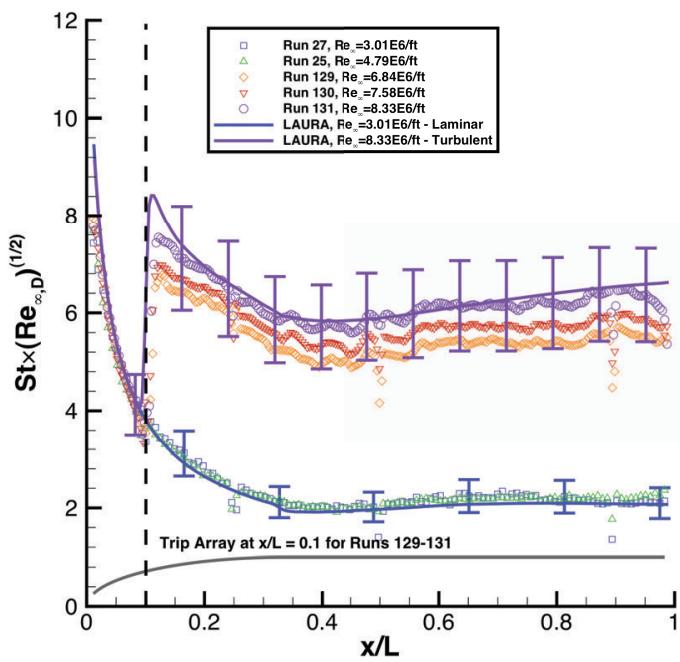

Ellipsled-2.00-0.50 with trips at $x / L=0.10$

Figure 27. Centerline Heating Comparisons for Ellipsled Configurations with Trips 
Table 5. Comparison of Heating Levels on Each Geometry

\begin{tabular}{|c|c|c|c|c|c|c|}
\hline \multirow[b]{2}{*}{ Geometry } & \multirow{2}{*}{$\begin{array}{c}\begin{array}{c}\text { Stagnation } \\
\text { Point }\end{array} \\
\text { Measured } \\
S t \times\left(R e_{\infty, \mathrm{D}}\right)^{(1 /} \\
\end{array}$} & \multicolumn{5}{|c|}{$\begin{array}{l}\text { Max Heating } \\
\text { Point on Body }\end{array}$} \\
\hline & & $\begin{array}{c}\text { Location } \\
(\mathrm{x} / \mathrm{L})\end{array}$ & $\begin{array}{c}\text { Boundary } \\
\text {-layer } \\
\text { state }\end{array}$ & $\begin{array}{c}\text { Measured } \\
S t \times\left(R e_{\infty, \mathrm{D}}\right)^{(1 / 2)}\end{array}$ & $\begin{array}{c}\text { LAURA } \\
\text { Laminar } \\
S t \times\left(R e_{\infty, \mathrm{D}}\right)^{(1 /}\end{array}$ & $\begin{array}{c}\text { Heating } \\
\text { Augmentation } \\
\text { (Measured/Laminar) }\end{array}$ \\
\hline Ellipsled-0.50-1.00 & 7.35 & 0.69 & Turbulent & 8.22 & 2.62 & 3.14 \\
\hline Ellipsled-1.00-1.00 & 5.98 & 0.94 & Transitional & 7.40 & 2.52 & 2.94 \\
\hline Ellipsled-2.00-1.00 & 7.00 & 0.80 & Laminar & 2.78 & 2.64 & 1.05 \\
\hline Ellipsled-2.00-0.50 & 7.59 & 0.97 & Transitional & 5.34 & 2.07 & 2.58 \\
\hline Ellipsled-2.00-0.25 & 8.35 & 0.73 & Turbulent & 6.75 & 1.74 & 3.88 \\
\hline COBRA-8459B & 7.78 & 0.95 & Transitional & 3.51 & 2.29 & 1.53 \\
\hline COBRA-14297B & 7.78 & 0.80 & Turbulent & 6.74 & 2.11 & 3.19 \\
\hline COBRA-14888B & 6.49 & 0.95 & Transitional & 7.31 & 2.06 & 3.55 \\
\hline Hammerhead-Blunt & 7.15 & 0.87 & Turbulent & 7.24 & 2.66 & 2.72 \\
\hline Hammerhead-Nominal & 7.80 & 0.91 & Turbulent & 7.53 & 2.61 & 2.89 \\
\hline Hammerhead-Sharp & 8.80 & 0.33 & Turbulent & 7.49 & 3.01 & 2.49 \\
\hline
\end{tabular}

\section{Summary and Conclusions}

Mid- $L / D$ entry vehicles have been proposed as an option to meet the aerodynamic performance requirements for high-mass missions to Mars and the outer planets. In order to provide data for mission concept development and system trade studies, the aerodynamics, convective heating, and boundary-layer transition characteristics of three families of Mid- $L / D$ vehicles: elliptically-blunted cylinders (Ellipsled family); optimized parametric geometries (COBRA family); and dual-use (ascent protection and aerocapture) launch vehicle shrouds (Hammerhead family), have been studied.

Aerodynamic performance estimates were produced using modified Newtonian theory. Of the 11 geometries considered, only the Ellipsled-0.50-1.00, Ellipsled-1.00-1.00, and Hammerhead-Blunt could not meet the desired requirement of $L / D$ of 0.4 to 0.8 . within angles-of-attack of 30-deg to 70-deg.

Boundary-layer transition behavior was determined from the global aeroheating measurements. All geometries experienced center-line, stream-wise boundary-layer transition except Ellipsled-2.00-1.00. Regions of fullydeveloped turbulent flow was produced on the Ellipsled-0.50-1.00, Ellipsled-2.00-0.25, COBRA-14297B, and all three Hammerhead geometries. In addition to stream-wise transition, "feathered" heating patterns indicative of cross-flow transition were noted on the Ellipsled-1.00-1.00 and Ellipsled-2.00-1.00, COBRA-8459B, and Hammerhead-nominal geometries.

Comparisons between predicted laminar heating levels and measured data along the centerline agreed to well within the experimental uncertainty for all configurations except for the Hammerhead family. On these geometries, a significant under-prediction was noted around the junction of the two cone-segments. This mismatch was attributed to insufficient grid-resolution at this geometric discontinuity. The use of an extrapolation-outflow boundary at the end of each geometry, in place of an end-cap and wake flow grid, also introduced some smaller mismatches between data and predictions at the aft end. However, both of these issues can likely be addressed through grid refinement and do not necessarily indicate any fundamental defect in the computational method.

Comparisons between transitional/turbulent data and predictions were less satisfactory. In regions of fullydeveloped turbulent flow, agreement to within the experimental uncertainty was achieved. However, this agreement was contingent on specification of the transition onset location and transition region length in the computations based on the data, rather than a priori prediction. Within the transition region, good agreement was not always obtained. Additionally, the algebraic turbulence and transition model employed does not provide a mechanism for modeling the observed cross-flow transition that occurred on several of the geometries.

While fully-turbulent predictions based on the algebraic turbulence model do bound the dataset and could be used for first-order mission design and analysis purposes, more precise and realistic predictions would require more complex computational models. The transition data from this study can be used to help develop more sophisticated correlations for stream-wise transition onset for algebraic turbulence/transition models. However, in order to better model the cross-flow transition and turbulence, it is likely that higher-fidelity turbulence modeling techniques will be required. 


\section{References}

1. Dwyer Cianciolo, A. M., Davis, J. L., Komar, D. R., et al, "Entry, Descent and Landing Systems Analysis Study: Phase 2 Report," NASA TM-2010-216720, July, 2010.

2. Dwyer Cianciolo, A. M., Davis, J. L., Engelund, W. C.., et al, "Entry, Descent and Landing Systems Analysis Study: Phase 1 Report on Exploration Feed-Forward Systems," NASA TM-2011-217055, February, 2010.

3. Cianciolo, A. D., Davis, J. L., Shidner, J. D., and Powell, R. W., "Entry, Descent and Landing Systems Analysis: Exploration Class Simulation Overview and Results," AIAA Paper 2010-7970, AIAA/AAS Astrodynamics Specialists Conference, Toronto, Ontario Canada, August 2-5, 2010.

4. Zang, T. A., Dwyer-Cianciolo, A. M., Kinney, D. J., et al, "Overview of the NASA Entry, Descent and Landing Analysis Study," AIAA Paper 2010-8649, AIAA SPACE 2010 Conference and Exhibit, Anaheim, CA, August 30 - September 2, 2010.

5. Lockwood, M. K., Edquist, K. T., Starr, B. R., Hollis, B. R., et al, “Aerocapture System Analysis for a Neptune Mission," NASA TM-2006-214300, April 2006.

6. Drake, B. G., "Reference Mission Version 3.0 Addendum to the Human Exploration of Mars: The Reference Mission of the NASA Mars Exploration Study Team,” NASA SP-1998-6107/ADD, June 1998.

7. Garcia, J. A., Brown, J. L., Kinney, D. J., et al, "Co-Optimization of Mid Lift to Drag Vehicle Concepts for Mars Atmospheric Entry," AIAA Paper 2010-5052, $10^{\text {th }}$ AIAA/ASME Joint Thermophysics and Heat Transfer Conference, Chicago, IL, June 28 - July 1, 2010.

8. "Human Exploration of Mars Design Reference Architecture 5.0," Drake, B. G., editor, NASA-SP-2009-566, July 2009.

9. Borowski, S. K., McCurdy, D. R., and Packard, T. W., "7-Launch NTR Space Transportation System for NASA's Mars Design Reference Architecture (DRA) 5.0," AIAA Paper 2009-5308, 45 ${ }^{\text {th }}$ AIAA/ASME/SAE/ASEE Joint Propulsion Conference and Exhibit, Denver, CO, August 2 - 5, 2009.

10. Micol, J. R. "Langley Aerothermodynamic Facilities Complex: Enhancements and Testing Capabilities," AIAA Paper 98$0147,36^{\text {th }}$ AIAA Aerospace Sciences Meeting and Exhibit, Reno, NV, January 12-15, 1998.

11. Buck, G. M., "Rapid Model Fabrication and Testing for Aerospace Vehicles," AIAA Paper 2000-0826, 38th AIAA Aerospace Sciences Meeting and Exhibit, Reno, NV, January 10-13, 2000.

12. Buck, G. M., "Surface Temperature/Heat Transfer Measurement Using a Quantitative Phosphor Thermography System," AIAA Paper 91-0064, January 1991.

13. Merski, N. R., "Global Aeroheating Wind-Tunnel Measurements Using Improved Two-Color Phosphor Thermography Methods, Journal of Spacecraft and Rockets, Vol. 36, No. 2, pp. 160-170, March-April 1999.

14. Fay, J. A., and Riddell, F. R., "Theory of Stagnation Point Heat Transfer in Dissociated Air," Journal of Aeronautical Sciences, Vol. 25, No. 2., pp. 73-85, February 1958.

15. Gnoffo, P. A., "An Upwind-Biased, Point-Implicit Algorithm for Viscous, Compressible Perfect-Gas Flows," NASA TP2953, February 1990.

16. Mazaheri, A., Gnoffo, P. A., Johnston, C. O., and Kleb, B., “LAURA User's Manual: 5.4-54166," NASA TM-2011217092, May 2011.

17. Cheatwood, F. M. and Thompson, R. A., "The Addition of Algebraic Turbulence Modeling to Program LAURA," NASA TM-107758, April 1993.

18. Hollis, B. R. "Blunt-Body Entry Vehicle Aerothermodynamics: Transition and Turbulence on the CEV and MSL Configurations," AIAA Paper 2010-4984, 40 ${ }^{\text {th }}$ Fluid Dynamics Conference and Exhibit, Chicago, IL, June 28 - July 1, 2010.

19. Dhawan. S., and Narashima, R., "Some Properties of Boundary Layer Flow from Laminar to Turbulent Motion," Journal of Fluid Mechanics, Vol. 1, Part 4, pp. 418-436, Jan. 1958. 